\title{
Improving Adhesion of Seasonings to Crackers with Hydrocolloid
}

\section{Solutions}

\section{THESIS}

Presented in Partial Fulfillment of the Requirements for the Degree Master of Science in the Graduate School of The Ohio State University

\author{
By \\ Matthew Armstrong, B.S. \\ Graduate Program in Food Science and Technology
}

The Ohio State University

2013

Master's Examination Committee:

Dr. Sheryl Barringer, Advisor

Dr. Luis Rodriguez-Saona

Dr. Yael Vodovotz 


\section{Copyrighted by}

Matthew Armstrong

2013 


\begin{abstract}
Food powders were applied on crackers that had been coated using water, oil, emulsion, sucrose, or hydrocolloid solutions. The hydrocolloids that were used include gellan gum, kappa-carrageenan, methyl cellulose, gum karaya, gum tragacanth, gum arabic, guar gum, modified starch, and maltodextrin. Solutions of similar hydrophobicity to the powder gave the greatest adhesion. $\mathrm{NaCl}$, barbecue (BBQ), ranch, and sour cream \& onion (SC\&O) seasoning showed greatest adhesion with water, cheese powder with an emulsion of 12.5-25\% oil, and cocoa powder with oil. For $\mathrm{NaCl}, \mathrm{BBQ}$, ranch, and SC\&O seasoning, hydrocolloids improved the adhesion over using water alone, with gellan gum providing the greatest adhesion. Hydrocolloid structural differences, including the presence or absence of branching, substitution of sugar units, and molecular weight were significant contributing factors to adhesion of powders to the target surface. For cheese powder, hydrocolloids were capable of replacing the oil within an emulsion while improving or maintaining the same level of adhesion, with gum arabic providing the greatest adhesion. For cocoa powder, hydrocolloid solutions were ineffective adhesives due to differences in hydrophilicity that result in insolubility. The effect of hydrocolloid concentration on adhesion was dependent on hydrocolloid type, with $0.5 \%$ being the optimum concentration for most gums. Adhesion using sucrose solutions was determined by particle size and relative hydrophobicity. Increasing sucrose concentration decreased
\end{abstract}


adhesion of smaller particles, but increased adhesion of larger particles. Adhesion of $\mathrm{NaCl}$ significantly increased with decreasing $\mathrm{NaCl}$ size using oil, water, and sucrose solutions. 


\section{Practical Applications}

Hydrocolloids can be used to replace oil and sugar to adhere powders and small particulates, such as seasonings, to a food surface while improving or maintaining the same level of adhesion. Replacement of oil and sugar by hydrocolloids would lower fat content and calories and would be of interest to the food industry. Solutions of similar hydrophobicity to the powder give the greatest adhesion; therefore, powder hydrophobicity should be considered when selecting solutions for adhesive purposes. 
Dedicated to my mother 


\section{Acknowledgments}

I would like to my advisor, Dr. Sheryl Barringer, for her perpetual guidance and support. She has been an inspiration through her devotion to science and to her students. I have benefited tremendously from her dedication and knowledge, and I consider myself extremely fortunate to have worked under her leadership.

Secondly, I would like to thank my committee members, Dr. Luis Rodriguez-

Saona and Dr. Yael Vodovotz, for their impact on my educational experience and the knowledge they imparted to me through the classes they taught.

I would like to express my sincere appreciation for my mother, Mary Ann Armstrong, for her unconditional love and support. She has had a tremendous impact on my life and has truly blessed me through her guidance.

Lastly, thank you to my friends and lab mates for their friendship and all of their support and encouragement. 
Vita

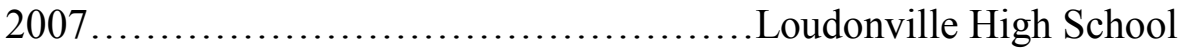

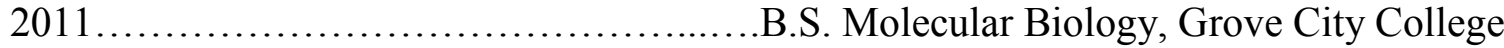

\section{Fields of Study}

Major Field: Food Science and Nutrition 


\section{Table of Contents}

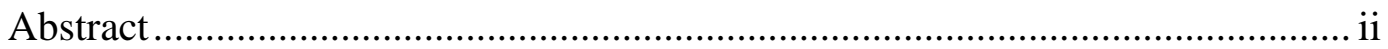

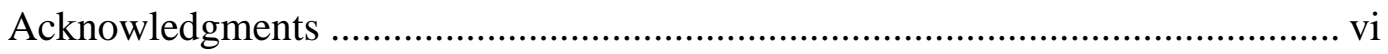

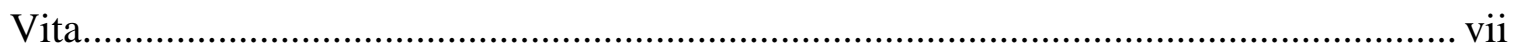

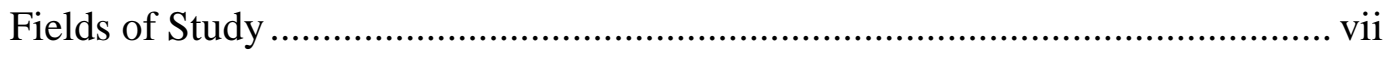

Table of Contents ............................................................................... viii

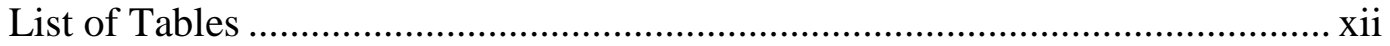

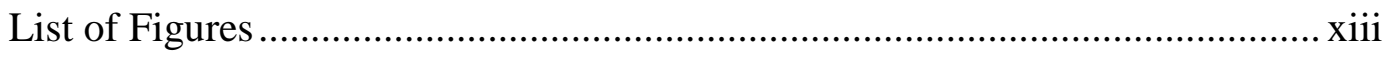

Chapter 1: Introduction ........................................................................... 1

Chapter 2: Literature Review.................................................................. 4

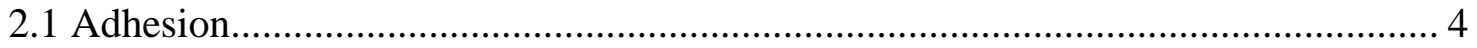

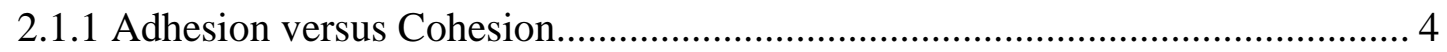

2.1.2 Theories and Mechanisms of Adhesion....................................................... 5

2.1.2.1 Interparticle Attraction Mechanisms............................................. 6

2.1.2.1.1 Intermolecular and Electrostatic Forces......................................... 6

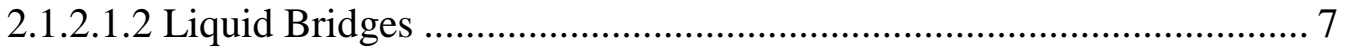


2.1.2.1.2.1 Mobile Liquid Bridges .......................................................... 8

2.1.2.1.2.2 Immobile Liquid Bridges ................................................... 9

2.1.2.1.3 Solid Bridges................................................................................ 10

2.1.2.1.4 Mechanical Interlocking and Surface Roughness .............................. 11

2.1.2.2 Wetting and the Theory of Thermodynamic Adsorption........................... 13

2.1.3 The Influence of Surface Tension on Adhesion .............................................. 14

2.1.4 Powder Properties ................................................................................... 15

2.1.4.1 The Influence of Particle Size on Adhesion ............................................. 15

2.1.4.2 The Influence of Geometry on Adhesion................................................... 17

2.1.4.3 The Influence of Hydrophilicity on Adhesion ......................................... 18

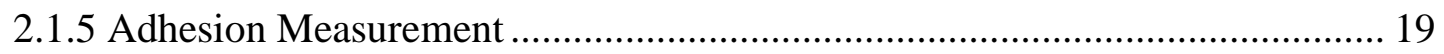

2.1.6 The Influence of Relative Humidity on Coating ............................................ 20

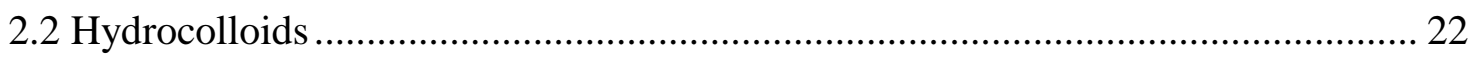

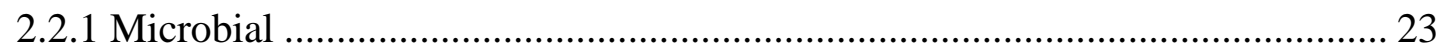

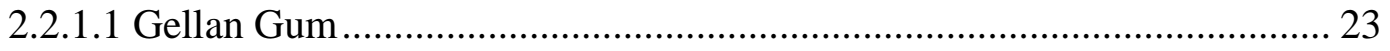

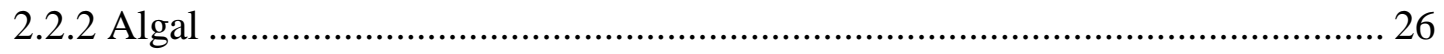

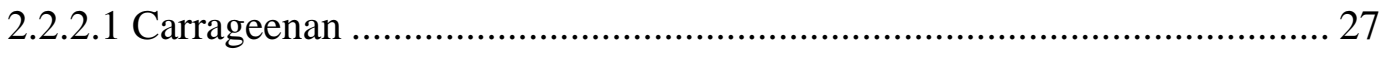

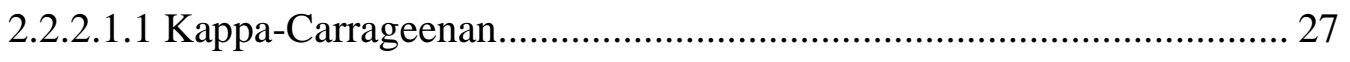

2.2.3 Tree Gum Exudates .............................................................................. 29

ix 


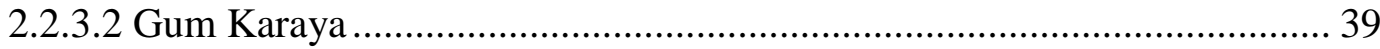

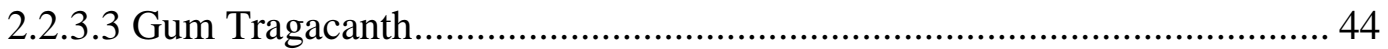

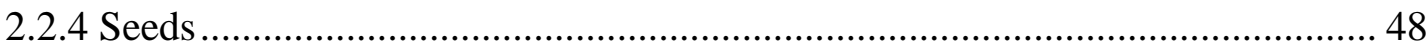

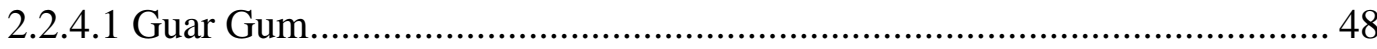

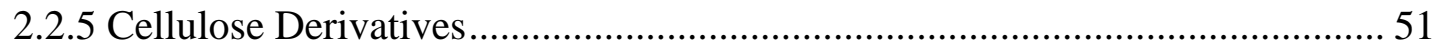

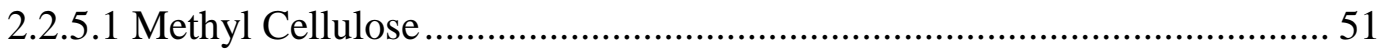

2.3 Analytical Methods for Particle Size Analysis .............................................. 54

2.3.1 Low Angle Laser Light Scattering ....................................................... 55

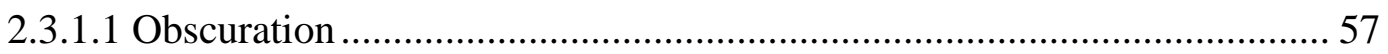

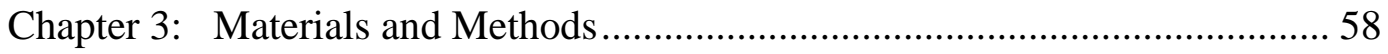

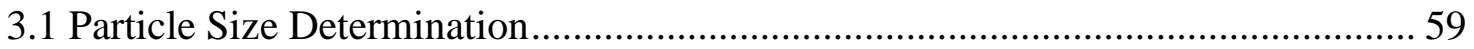

3.2 Powder Hydrophobicity Determination ........................................................ 59

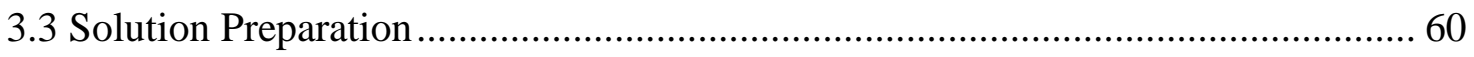

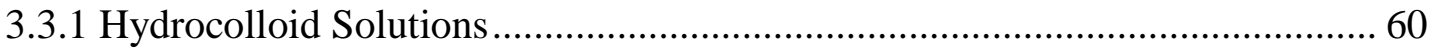

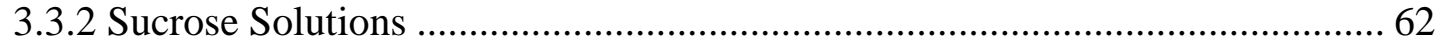

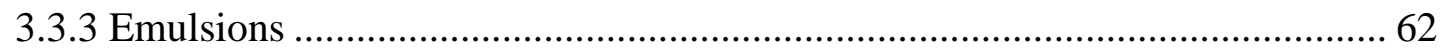

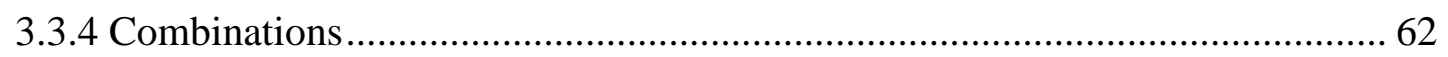

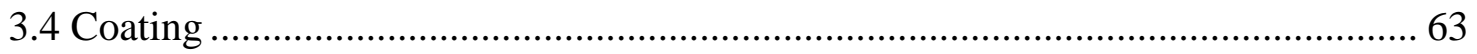




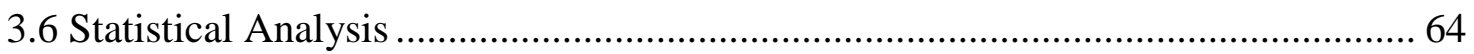

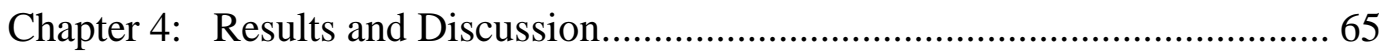

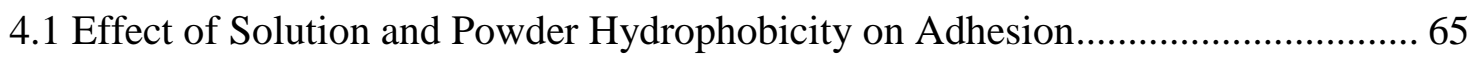

4.2 Effect of Hydrocolloid Type on Adhesion .................................................... 71

4.3 Effect of Hydrocolloid Concentration on Salt Adhesion ................................... 81

4.4 Effect of Solution Sucrose Concentration on Adhesion...................................... 82

4.5 Effect of Salt Size on Adhesion .................................................................... 86

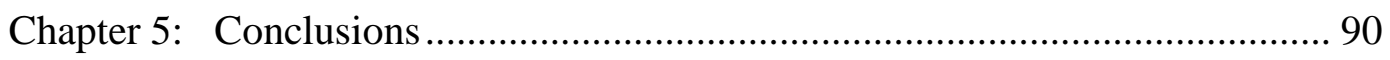

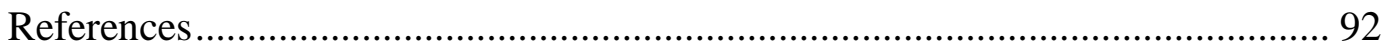

Appendix A: Particle Size of Powders ...................................................... 107

Appendix B: Solution Concentration....................................................... 108

Appendix C: Powder Hydrophobicity ..................................................... 109 


\section{List of Tables}

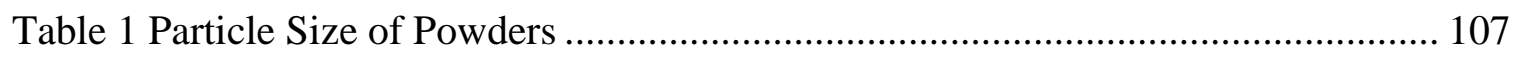

Table 2 Solution Concentrations Capable of being Sprayed ..................................... 108

Table 3 Partition of Powder Components into Aqueous and Cyclohexane or Hexane

Phases for Determination of Powder Hydrophobicity ........................................... 109 


\section{List of Figures}

Figure 4.1 Effect of solution hydrophobicity on fine $\mathrm{NaCl}, \mathrm{BBQ}, \mathrm{SC} \& \mathrm{O}$, cheese A, cheese B, and cocoa powder adhesion measured by moderate (top) and severe (bottom) methods. Means that share a letter within a powder group are not significantly different.

Figure 4.2 Images of crackers coated with BBQ seasoning (top) and cocoa powder (bottom) using five solutions ranging from 0-100\% oil.

Figure 4.3 Effect of hydrocolloid type on fine and coarse $\mathrm{NaCl}$, SC\&O, ranch, and $\mathrm{BBQ}$ seasoning adhesion. Means that share a letter within a powder group are not significantly different.

Figure 4.4 Effect of hydrocolloid type on cheese powder A and B and cocoa powder adhesion. Means that share a letter within a powder group are not significantly different.

Figure 4.5 Effect of hydrocolloid combinations on SC\&O and BBQ seasoning adhesion. Means that share a letter within a powder group are not significantly different. 80 Figure 4.6 Effect of hydrocolloid concentration on fine $\mathrm{NaCl}$ adhesion. 82 
Figure 4.7 Effect of sucrose concentration on 58, 354, 394, 431, and $484 \mathrm{um} \mathrm{NaCl,} \mathrm{BBQ,}$ ranch, SC\&O, cheese B, and cocoa powder adhesion. Means that share a letter within a powder group are not significantly different.

Figure 4.8 Effect of $\mathrm{NaCl}$ size on adhesion using water, 50\% sucrose solution, and oil.

Means that share a letter are not significantly different........................................ 88 


\section{Chapter 1: Introduction}

Adhesion plays an important role in product quality, determining appearance and taste as well as waste of seasoning. Traditionally, sugar and oil have been used to adhere powders and small particulates, such as seasonings, to a food surface, but consumer interest in low- or no-fat and calorie products means there is an interest in discovering alternatives.

Adhesion is the physical phenomenon by which two materials stick together and covers both the establishment of interfacial bonds as well as the mechanical load required to result in failure of the bonded assembly (Michalski and others 1997; Amara and others 2007). The attractive forces which hold particles together when they come into close contact depend on the physical characteristics of the individual particles and the nature of the physical process by which the particles interact (Papadakis and Bahu 1992). Foods are complex and varied in their composition and structure; therefore, it is difficult to apply some adhesion theories as overall laws to all types of products.

The relationship between solution hydrophobicity and adhesion is determined by the affinity of the powder towards the solution based on relative hydrophilicity Liquids interact with solid particles composed of molecules of similar polarity (Dopfer and others 2012). A solid that has a strong affinity toward a liquid is likely to adhere well (Michalski and others 1997). Addition of sterols yields better adhesion between fruit and vegetable 
surfaces and coating films due to better compatibility with respect to the hydrophobicity of the two adhering surfaces (Nussinovitch and Hershko 1996). Adhesion of $\mathrm{NaCl}$ has been found to increase with increasing surface oil content, but comparisons have not been made to hydrophilic solutions or to the use of different food powders (Enggalhardjo and Narsimhan 2005; Buck and Barringer 2007).

Hydrocolloid structural differences, including the presence or absence of branching, substitution of sugar units, and molecular weight are significant contributing factors to differences in hydrocolloid functionality. Gum arabic possesses unique structural components that give rise to emulsification properties that set it apart from other hydrocolloids (Dickinson and others 1989). The arabinogalactan-protein complex of gum arabic contains polypeptides along the periphery that enable the molecule to adsorb onto hydrophobic surfaces and explain its ability to sterically stabilize emulsions and dispersions (Randall and others 1988, 1989). Adhesive properties of hydrocolloids have been shown to be dependent on the specific hydrocolloid used and on concentration (Ben-Zion and Nussinovitch 1997).

The effectiveness of sugar solutions as an adhesive is dependent on solution sucrose concentration. Adhesion of $400 \mathrm{um} \mathrm{NaCl}$ significantly increased as concentration of sucrose or glucose in the solution increased (Ren and Barringer 2009). Similarly, adhesion between sesame seeds increased as surface sucrose content increased (Takenaka and others 2006).

Particle size affects intermolecular forces and material bridges that determine adhesion rates; therefore, particle size is important. Adhesion of salt to food targets 
including carrot, bread, lettuce and cracker significantly increased with decreasing salt size from 332 to $119 \mu \mathrm{m}$ (Sumonsiri and Barringer 2011). Adhesion of salt to a potato chip surface significantly increased with decreasing salt size from 388 to $25 \mu \mathrm{m}$ (Buck and Barringer 2007). The effect of particle size on adhesion is based in the fact that the ratio of particle adhesion to particle weight is inversely proportional to the square of the particle size (Schubert 1987). This inverse relationship results in an increase in surface area per unit volume. As a result of the increase in surface area per unit volume, surface forces become dominant over gravitational forces in small particulates (Adhikari and others 2001).

The objective of this study was to determine if hydrocolloids could be used to replace oil and sugar while improving or maintaining the same level of adhesion, which would lower calories and be of interest to the food industry. 


\section{Chapter 2: Literature Review}

\subsection{Adhesion}

Adhesion is the physical phenomenon by which two materials stick together (Michalski and others 1997). Stickiness is the textural property manifested by a tendency to adhere to contacting surfaces and is influenced by contact force and contact time (Kilcast and Roberts 1997). Adhesion has been quantified as the work done in separating 2 surfaces that are in contact with each other (Michalski and others 1997; Enggalhardjo and Narsimhan 2005). Adhesion of powders to targets is of primary importance in numerous industries, especially in the snack food industry where adhesion plays an important role in product quality, determining appearance and taste, as well as waste of seasoning.

\subsubsection{Adhesion versus Cohesion}

Adhesion is an interfacial property and is a measure of the forces holding the powder to the surface of another material while cohesion is an internal property of the powder and is a measure of the forces holding the particles together. Particles will stick to a surface or to each other unless the bond between them is broken by applying forces greater than the adhesive or cohesive force respectively. The mechanisms causing a 
powder to be cohesive or adhesive are similar but high cohesion is not always associated with high adhesion and vice versa (Papadakis and Bahu 1992). Particles first adhere on a surface in a monolayer. At this point, each particle occupies a position of closest proximity to the surface and interacts directly with the surface. Monolayer power is a function of adhesive forces, representing the interactions of a single layer of particles with the adjacent surface. Particles then begin to build up on top of the initial monolayer to form a multilayer, where each new layer is more remote from the substrate surface than the preceding layer. Multilayer powder is a function of adhesive and cohesive forces. Adhesive interactions between the monolayer and the target surface are important in multilayer powder as well as the cohesive interactions between the monolayer and the subsequent powder layers. The forces experienced between the substrate surface and each subsequent layer decreases as the distance of separation increases.

\subsubsection{Theories and Mechanisms of Adhesion}

Foods are complex and varied in their composition and structure; therefore, it is difficult to apply some adhesion theories as overall laws to all types of products. The term adhesion covers both the establishment of interfacial bonds as well as the mechanical load required to result in failure of the bonded assembly (Amara and others 2007). The force of particle adhesion is equivalent in magnitude to the force required for particle detachment (Louey and others 2000). True adhesive failure occurs if there is a clean failure of the bond between adhesive and adherend, with no residual adhesive remaining on the adherend surface. If adhesive does remain on the surface, cohesive 
failure within the adhesive has occurred (Kilcast and Roberts 1997). Mechanisms involved in adhesive process between materials are related to many fields of knowledge, including mechanics, thermodynamics, and chemistry (Michalski and others 1997). In practice, several adhesion mechanisms can be involved simultaneously; however, it is generally considered that the thermodynamic theory offers the main mechanism with the widest applicability (Amara and others 2007).

\subsubsection{Interparticle Attraction Mechanisms}

Mechanisms of interparticle attraction have been divided into five major groups: intermolecular and electrostatic forces, mobile liquid bridges, immobile liquid bridges, solid bridges, and mechanical interlocking. The attractive forces which hold particles together when they come into close contact depend on the physical characteristics of the individual particles and the nature of the physical process by which the particles interact (Papadakis and Bahu 1992). These forces vary in magnitude and the manner in which they are transmitted.

\subsection{Intermolecular and Electrostatic Forces}

Cohesion between two particles and adhesion between two surfaces without material bridges is primarily attributable to van der Waal's and electrostatic forces (Schubert 1987; Adhikari and others 2001). Electrostatic adhesion involves long-range

electrostatic and electrodynamic interactions and occurs where particles possess excess opposing charges. Van der Waals forces are related to electromagnetic fluctuation 
phenomena in solids. If particles are sufficiently close to each other, van der Waals attractive forces result from local polarizations induced by randomly excited electrons generating electric and magnetic fields within solids and within the dielectric medium in between (Massimilla and Donsi 1976). Van der Waals force is at a maximum when particles are in intimate contact with each other. The presence of immobile adsorbed liquid films on the surface of the particles will increase the magnitude of van der Waals attractive force through a decrease in the effective interparticle distance (Papadakis and Bahu 1992). If the effective interparticle distance is not decreased, the presence of liquid is found to shield van der Waals and electrostatic interactions, thus weakening these adhesion forces (Soltani and Ahmadi 1994). Van der Waals attractive forces are generally much lower than the forces resulting from mobile liquid bridges.

\subsection{Liquid Bridges}

Adhesion and cohesion between surfaces is a strong function of liquid bridges. In liquid bridges, particle surfaces are held together by binding forces originating from the liquid between particles. If a liquid forms a bridge between two particles, a force acts between them consisting of two components, the surface tension force, and a force due to the difference of the pressure outside and inside the bridge (Schubert 1984). Attractive capillary forces develop as a consequence of the formation of liquid bridges between contacting bodies. (Massimilla and Donsi 1976). The capillary forces of a liquid bridge originate from the attractive force caused by the surface tension and pressure deficiency across the liquid interface due to the curvature of the bridge surface (Murase and others 
2008). While the surface tension force always brings about an attraction, the capillary pressure can only contribute a positive component to the adhesion force, if it produces a pressure deficiency within the bridge (Schubert 1984). Liquid bridges result in a combined pull of solid particles by negative pressure and interfacial tension exerted by the liquid along the wetted perimeter (Adhikari and others 2001). Liquid bridges can be divided into two major groups: mobile and immobile.

\subsection{Mobile Liquid Bridges}

Mobile liquid bridges can be further subdivided into three groups based on the extent that liquid occupies the space between particles: pendular, funicular, and capillary. In mobile liquid bridges, the adhesion of the liquid to the solid and the cohesion within the liquid are of sufficient magnitude to transmit tensile stress and to sustain the capillary pressure (Papadakis and Bahu 1992). The theoretical granule strength in the capillary state is approximately three times greater than that in the pendular state, and the funicular state has an intermediate strength. The strength possessed by these states is influenced by liquid surface tension, porosity of the agglomerate, and the particle diameter (Adhikari and others 2001).

In the pendular state, liquid only occupies a portion of the total void space between particles. Non-interconnected liquid bridges develop between individual particles due to the limited volume filled by liquid (Massimilla and Donsi 1976). At the solid-liquid-gas interface, the surface tension is directed along the liquid surface while a negative capillary pressure exists in the liquid bridge (Papadakis and Bahu 1992). Both 
components result in mutual attraction of the particles, but only the interfacial forces at the liquid-gas interface contribute to the bonding force (Papadakis and Bahu 1992).

The funicular state is the transition between the pendular state and the capillary state. In the funicular state local liquid bridges coexist with interparticle spaces filled up with liquid (Massimilla and Donsi 1976). Gas is present within the voids between particles, but the liquid forms a continuous network similar to what is seen in the capillary state.

In the capillary state, the void space is completely filled with liquid and the interfacial forces exist only at the surface of the agglomerates and give rise to binding forces (Schubert 1984). A negative capillary pressure exists in the entire liquid space as a result of the liquid extending to the edge of the pores where it forms concave surfaces as seen from the gas side (Papadakis and Bahu 1992). The capillary state possesses the greatest strength as a result of the void space between particles being completely filled by liquid.

\subsection{Immobile Liquid Bridges}

Immobile liquid bridges are stronger than mobile liquid bridges and come into existence when thin layers of viscous binders are introduced between particles (Adhikari

and others 2001). When an immobile liquid bridge is stressed the adhesional forces at the solid-liquid interface and the cohesional forces in the binder are utilized up to the point where the weaker one is overcome (Papadakis and Bahu 1992). This increases the 
bonding strength of immobile liquid bridges by orders of magnitude over the bonding strength of mobile liquid bridges (Papadakis and Bahu 1992).

\subsection{Solid Bridges}

Solid bridges can be formed in several ways depending on the conditions that are present. Elevated temperatures can lead to a bridge of molten material where molecules diffuse from one particle to another at the point of contact to form a solid bridge. If the base powder has appreciable solubility in the granulating fluid, the solid bridges will be formed by recrystallization (or precipitation) of the base powder as the bridge dries (Bika and others 2005). Depending on the solubility of the particles adhered and the solubility of the surface material moisture can result in strong irreversible solid bridge bonds or in weak solid bridge bonds that are of comparable strength to van der Waals forces (Podczeck and others 1997). The formation of solid bridges through crystallization of dissolved materials is known as the recrystallized bridge model.

In the recrystallized bridge model, the binder liquid dissolves considerable amounts of solids at the time of formation of the liquid bridges (Adhikari and others 2001). These wet granules are subsequently dried and liquid evaporates from the bridges to leave behind solid bridges that impart mechanical strength to the system (Bika and

others 2005). The strength of this bond depends not only on the amount of solid deposited but also on the crystal structure (Papadakis and Bahu 1992).

Immobile liquid bridges can transform into solid bridges through subsequent drying of the binder in a similar manner to the recrystallized bridge model. The key 
difference in this mechanism is that primary particles are not dissolved into the binder liquid. Bika and others (2005) reported that in systems where the base-powders were only very slightly soluble in the granulating solution the main binding agent was the polymer. The mechanism of immobile liquid bridge transformation into solid bridge is viscous flow driven by surface energy. (Downton and others 1982).

In most cases, the solid bridge is assumed to be nonporous and of similar chemical composition and physical properties as either the primary particles or the polymeric binder (Bika and others 2005). The dissolution of primary particles into the liquid binder has an important influence on the composition of the bridge. Assuming some solubility of primary particles in the fluid, the liquid bridges are multicomponent solutions that may form solid bridges of complex microstructure when dried (Bika and others 2005).

\subsection{Mechanical Interlocking and Surface Roughness}

The theory of mechanical interlocking attributes the origin of adhesion to the anchoring or bonding of the adhesive in the pores or superficial asperities of the surface (Amara and others 2007). These effects appear on a macro-scale, but are also important on a micro-scale (Michalski and others 1997). Macroscopic substrate roughness provides a mechanical locking of the particle and a large surface area for bonding (Mittal 1977). Surface roughness has been found to be among the key factors responsible for adhesion (Adhikari and others 2007). Surface roughness improved adhesion by increasing the number of hooking sites and by increasing friction between materials (Michalski and 
others 1997). More mechanical interlocking occurs when particle size is smaller than the pore size of the surface.

In the case of van der Waals forces and very small liquid bridges, adhesion is determined almost entirely by the size and shape of the roughness peaks (Schubert 1987). Target surface roughness affects the true contact area, which in turn affects strength of the van der Waals force. The nature of the roughness, including the peak-to-peak distance between asperities and the height of asperities, determines the degree to which van der Waals force is affected. Surface roughness is of great significance in the case of particles in which surface roughness increases the separation distance (Schubert 1987). If surface asperities are much smaller than particles, less mass is present in the immediate vicinity of the contact plane resulting in reduced adhesion force (Ranade 1987). Adhesion forces between real particles are frequently smaller by more than an order of magnitude than the values calculated for perfectly smooth model solids (Schubert 1987).

Liquid used as an adhesive solution or that accumulated via capillary condensation is affected by surface roughness in a similar manner as adhered particles. If there is no intimate contact between the adhesive solution and the substrate surface or the particle surface, the increased roughness can lead to decreased adhesion by producing uncoated areas of voids or vacancies (Mittal 1977). Adhesion depends on the relation between the height of the surface peaks and the thickness of the adsorbed layer of water (McFarlane and Tabor 1950). The adsorbed layer must become sufficiently thick to engulf the surface asperities before capillary forces can become dominant. Van der Waals forces are dominant prior to engulfment of the asperities. 


\subsubsection{Wetting and the Theory of Thermodynamic Adsorption}

Wetting and the theory of thermodynamic adsorption are particularly well adapted for food adhesion, as many food products are liquid and flow on a solid surface. Wetting is the extent that a liquid drop spreads on a solid surface. A good wettability means that liquid and solid have a strong affinity and are likely to adhere well (Michalski and others 1997). The time taken for a liquid to wet a surface will increase with increasing viscosity, and in the case of adhesive/adherend interactions this may influence tack, which is the property that enables an adhesive to form a bond with the surface of another material upon brief contact under light pressure (Kilcast and Roberts 1997). Reduced viscosity greatly enhances the molecular mobility of the system, which is linked to liquid and solid bridges and also to textural characteristics like stickiness and adhesion (Adhikari and others 2001).

It has been demonstrated that adhesion occurs at intimate contact between neighboring materials and that adequate wetting was a necessary condition for good adhesion (Shanahan 1991). With decreasing wettability of the solid surface, the binding forces are reduced and thus the strength too (Schubert 1984). Sufficient wetting between materials can be reached if materials are close enough because of the short action distance of intermolecular forces that govern wetting phenomena linked to thermodynamic absorption (Michalski and others 1997). Complete wetting of the surface will occur when the surface energy of the adherend is greater than that of the adhesive due to the fact that low-energy materials absorb strongly to high-energy surfaces to lower 
the surface energy of the system (Kilcast and Roberts 1997). The presence of water on particle surfaces can reduce surface micro-roughness; thereby allowing them to come closer, which then increases the forces of attraction between the particles (Adhikari and others 2001).

\subsubsection{The Influence of Surface Tension on Adhesion}

Surface tension indicates how strongly the surface molecules of a liquid/solution are attracted by the adjacent molecules and is a factor affecting stickiness (Adhikari and others 2007). It was found that surface roughness, the yield stress of the sample and solid surface tension were the key factors responsible for adhesion (Adhikari and others 2007). The extent of liquid bridge formation between particles is dependent on the properties of the solid-liquid system under consideration, including surface tension of the liquid (Massimilla and Donsi 1976). Formation of liquid bridges contributes significantly to the attractive force exhibited between particles through the development of capillary forces. Capillary forces are dependent on liquid surface tension, and water creates significant surface tension (Ranade 1987). The meniscus that is created during the formation of liquid bridges draws the particles together due to surface tension and reduces the pressure of the liquid (Ranade 1987). The force caused by surface tension and the force caused by capillary pressure cause an attractive force between particles. Using a particle adhesion model, adhesion force was shown to exhibit a slight decrease with a decrease in surface tension, which can be attributed to the decrease in capillary force (Enggalhardjo and Narsimhan 2005). Surface tension was found to better correlate with surface stickiness 
compared to viscosity in fructose, maltodextrin, lactose and whey protein isolate solutions (Adhikari and others 2007). In these same solutions, surface stickiness was shown to increase as surface tension increased (Adhikari and others 2007).

\subsubsection{Powder Properties}

\subsubsection{The Influence of Particle Size on Adhesion}

Particle size has a profound influence on the cohesive and adhesive strength of a particulate system (Adhikari and others 2001). Van der Waals, electrostatic, and capillary forces increase with increasing particle size, contributing to a greater total adhesion force using a particle adhesion model (Enggalhardjo and Narsimhan 2005). Enggalhardjo and Narsimhan (2005) reinforced the adhesion model, showing that adhesion force of dry seasoning particles onto tortilla chips increased with increasing particle size from 32-300 $\mu \mathrm{m}$. However, the ratio between adhesion force and particle weight is more important than the absolute value of the adhesion force (Schubert 1987).

Interparticle adhesion usually increases in proportion to particle size, but the ratio of particle adhesion to particle weight is inversely proportional to the square of the particle size (Schubert 1987). The inverse relationship between the ratio of particle adhesion to particle weight and the square of particle size causes an increase in surface area per unit volume and is the basis behind why small particles to adhere much more strongly to each other and to surfaces than large particles. For example, the adhesion

force to weight ratio for particles of $1 \mu \mathrm{m}$ is larger by a factor of $10^{6}$ than for particles of 
$1 \mathrm{~mm}$ diameter (Schubert 1987). As a result of the increase in surface area per unit volume, surface forces become dominant over gravitational forces in small particulates (Adhikari and others 2001). The smaller the particle diameter, the larger the van der Waals force and capillary force with respect to particle weight force (Massimilla and Donsi 1976).

Particle size influences particle contact area and the void space dimensions between particles. Adhesion of sugar onto saltine crackers decreased with increasing particle size from $23-443 \mu \mathrm{m}$ because increasing particle size decreases the particle contact area which decreases the attraction force (Halim and Barringer 2006). Strength of van der Waals force is dependent on contact area and the distance between two surfaces and is at a maximum when particles are in intimate contact with each other. Increasing particle size decreases the strength of van der Waals force through an increase in interparticle distance and a decreases particle contact area. The influence of particle size on void space dimensions between particles affects capillary pressure and thus liquid bridges which are dependent on capillary forces. Solid bridges are similarly affected by interparticle distance. Smaller bridges resulting from smaller distances between particles develop higher strength as the solvent evaporates (Tardos and Gupta 1996).

The increased total adhesion force in relation to particle weight demonstrated by small particles has been reported to significantly affect food systems. Adhesion of salt to potato chip surface significantly increased with decreasing salt size from 388-25 $\mu \mathrm{m}$ (Buck and Barringer 2007). Sumonsiri and Barringer (2011) reported that adhesion of salt to food targets including carrot, bread, lettuce and cracker significantly increased with 
decreasing salt size from 332-119 $\mu \mathrm{m}$. Increased adhesion rates with small particles in comparison to large particles arise due to the strengthening of intermolecular forces and material bridges.

\subsubsection{The Influence of Geometry on Adhesion}

Particle shape is an important adhesion factor and affects the geometry of the gap between contacting surfaces and the available surface area. Van der Waals interactions occur over a finite distance range and depend in part on the geometry of the gap between the bodies (Massimilla and Donsi 1976). Particle shape determines the separation distance experienced between surfaces and the degree to which this separation distance varies throughout the gap. The strength of van der Waals force is dependent on contact area and the distance between two surfaces and varies as the distance between particles varies. Certain particle geometry may prevent particles from becoming sufficiently close to each other in non-contact regions and prevent the development of van der Waals force in these areas.

Material bridging and mechanical interlocking are also affected by particle geometry. At a given temperature, the extent of the liquid bridge depends on the geometry of the gap between the contacting bodies and several other factors (Massimilla and Donsi 1976). The strength of capillary forces that develop as a consequence of liquid bridge formation is dependent on how particles pack and the shape and size of the void space between particles. Contact geometry is dependent on particle shape and affects the accumulation of moisture during liquid bridge development (Schubert 1984). Surface 
roughness and the amount of surface area available for bonding are related to particle shape. Therefore, powder shape affects mechanical interlocking and the number of contact points (Michalski and others 1997).

The effect of particle geometry on adhesion is affected by particle size and substrate surface properties. Buck and Barringer (2007) compared adhesion between cubic, flake, and dendritic salts onto potato chip surfaces and reported that shape had a greater effect on adhesion for larger salts $(370-388 \mu \mathrm{m})$ than small salts $(239-259 \mu \mathrm{m})$. Surface area and the geometry of the particle determine how well salt adheres to a food product (Kuntz 1994). However, Buck and Barringer (2007) reported that cubic and flake salts showed greater adhesion that dendritic salt despite dendritic crystals possessing the highest surface area.

\subsubsection{The Influence of Hydrophilicity on Adhesion}

The effect of particle hydrophilicity on adhesion is largely due to its influence on wetting. Contact angle is commonly used to describe the relative hydrophobicity/hydrophilicity of a surface and is the angle at which a liquid/vapor interface meets a solid surface. Hydrophilic materials exhibit contact angles close to $0^{\circ}$ while less strongly hydrophilic material exhibit contact angles up to $90^{\circ}$. Highly hydrophobic surfaces exhibit contact angles up to $180^{\circ}$. Wetting of the surface increases as contact angle approaches $0^{\circ}$. The interfacial area of contact is increased as contact angle decreases, which results in improved adhesion (Mittal 1977). Adhesion depends on the wetting angle of the material for particles adhered to the surface by capillary force 
due to the presence of moisture. Capillary forces have their greatest effect on a hydrophilic surface, wetting angle near $0^{\circ}$, and their least effect on a hydrophobic surface, wetting angle near $90^{\circ}$ (Papadakis and Bahu 1992). With decreasing wettability of the solid surface, the binding forces are reduced and thus the strength too (Schubert 1984). Adhesion of hydrophilic particles at high relative humidity could be described by capillary bridging but this could not be applied to hydrophobic surfaces (Podczeck and others 1996, 1997).

\subsubsection{Adhesion Measurement}

Many methods have been developed to determine adhesion strength between materials; however, many of these methods are suited only to a specific application. Evaluating adhesion or stickiness based on weighing the material remaining on the contact surface is the simplest method. A monolayer of food sticks on the adhered surface because of adhesive force and the remaining mass may simply remain there because of cohesive force (Adhikari and others 2001). As adhesive forces decrease with distance, further molecular layers can only keep attached due to cohesive forces (Michalski and others 1997).

Adhesive loss measurements are another method to evaluate adhesion. This method, established by Suderman and Cunningham (1983), consists of determining the amount of bread crumbs lost during shaking in a mechanical shaker, which was expressed as the percentage of breading loss (Michalski and others 1997). It should be stressed that this method will mostly characterize cohesion rather than adhesion; as an important part 
of the material lost will come from the outer layers and not what is on the contact surface (Michalski and others 1997).

\subsubsection{The Influence of Relative Humidity on Coating}

Relative humidity is the ratio of the amount moisture in a given volume of air to the amount that it is capable of holding, and is measured as a percentage at a given temperature. When dry powders are exposed to the atmosphere, adsorption of water molecules takes place on the particle surface. Ketkar and Keller (1975) reported that the effects of the adsorbed water layers on particle adhesion became significant above $72 \%$ relative humidity or when the number of monolayers of water exceeded five on a calcite surface. The extent of adsorption depends upon the relative humidity of the surrounding atmosphere and the affinity of the particles for water molecules. Hydrophilic substances showed an exaggerated effect of relativity humidity on the force of adhesion of small particles when compared to much less hydrophilic materials (Bradley 1932). The influence of adsorbed moisture on particle adhesion is not straightforward, and is expected to depend on the thickness of the adsorbed layer, the surface roughness, the surface chemistry, the contact geometry and any dissolution, intra-particle absorption or chemical changes that might arise due to the presence of water (Cleaver and Tyrrell 2004).

Capillary condensation will occur as the humidity approaches saturation and moisture will be present mainly in the form of liquid bridges at points where neighboring particles or adsorption layers are in direct contact (Schubert 1984). As the adsorbed water 
layer increases in thickness the van der Waal's force of attraction significantly decreases (Ketkar and Keller 1975). Capillary condensation at the particle-surface contact region can occur at relative humidities of about 60-70\% (Ranade 1987). Capillary condensation results in the formation of a meniscus in the gap between surfaces. Meniscus formation might also occur due to addition of a certain amount of liquid to the powder (Butt and others 2011). Ketkar and Keller (1975) reported that for the adhesion of limestone particles to a coal substrate at $75 \%$ relative humidity the water meniscus became the significant factor in the force of adhesion, and that the force of adhesion increased dramatically as relative humidity increased above $75 \%$ and reached a maximum above $95 \%$ relative humidity. Christenson (1988) reported that maximum adhesion between two mica surfaces was reached at 70\% relative humidity. Billings and others (2006) reported that the onset of significant liquid bridge formation between sugar particles occurs between relative humidities of 75-80\%. Huang and Barringer (2012) reported that there was no significant change in adhesion between starch powder and the targets when relative humidity increased from 30 to $60 \%$, while adhesion increased when relative humidity increased from 60 to $80 \%$. The increased adhesion at higher relative humidity coincides with the formation of liquid bridges from the condensation of atmospheric moisture.

The meniscus that is formed draws the bodies together due to surface tension and causes a reduction in the pressure of the liquid (Ranade 1987). The surface tension force and the reduction in capillary pressure generate an attractive force, capillary adhesion force, which is typically stronger than the van der Waals attraction (Butt and others 
2011). The capillary adhesion force of the liquid bridge increased with increasing relative humidity (Ranade 1987; Butt and others 2011). The relative humidity that maximum adhesion occurs at is system specific and depends on the hydrophilicity and the surface roughness (Cleaver and Tyrrell 2004). The increase in adhesion force with relative humidity must be accounted for through the presence of the water through surface tension forces since the van der Waal's force decreases monotonically with an increase in water film thickness (Ketkar and Keller 1975).

A liquid bridge is considered stable if its vapor pressure equals the partial pressure of the water vapor in the surrounding air (Schubert 1984). Podczeck and others (1997) reported that storage at low-relative-humidity conditions of about 5\% and room temperature can destroy the capillary force by removal of the moisture comprising the liquid bridge.

\subsection{Hydrocolloids}

Hydrocolloids are a diverse group of long chain polymers characterized by their rheological and gelation properties when dispersed in water. These compounds are hydrophilic and have a high affinity for binding water molecules because of the large number of hydroxyl groups characterizing their structure. When added to water these compounds produce a dispersion rather than a true solution or a suspension and exhibit the properties of a colloid. Rheological behavior, gelling properties, and other physical behaviors of hydrocolloids are directly related to structural features. Linear 
polysaccharides occupy greater volume and thus exhibit greater viscosity than branched polymers of comparable molecular weight at the same concentration. Many hydrocolloids are known for their swelling properties which are due to the entrapment of water between their chains and branches. Hydrocolloids have diverse structural properties and originate from a wide variety of sources including microorganisms, algae, tree gum exudates, and seeds.

\subsubsection{Microbial}

Microbial polysaccharides include gellan gum, xanthan gum, curdlan, dextran, pullulan, and bacterial cellulose. The molecular structure and chemical composition of microbial polysaccharides differs considerably which results in a wide spectrum of physicochemical properties. Microbial polysaccharides are widely used as thickening, gelling, stabilizing, emulsifying, and water-binding agents in the food, pharmaceutical, and cosmetic industries.

\subsubsection{Gellan Gum}

Gellan gum is an anionic extracellular heteropolysaccharide produced by the microorganism Sphingomonas elodea. Synthesis of polysaccharides via microbial fermentation offers several benefits to plant polysaccharides including minimal variation in product parameters (Khan and others 2007). The primary structure of gellan gum is composed of a linear tetrasaccharide repeat unit of D-glucose, D-glucuronic acid, D-

glucose, and L-rhamnose (Jansson and Lindberg 1983; O’Neil and others 1983) and is in 
a slim and extended shape (Chandrasekaran and others 1988b). Native gellan gum contains a considerable amount of non-polysaccharide material, including $10 \%$ cellular protein components, which can be removed by either filtration or centrifugation during clarification (Kang and others 1982). In the native or high acyl form, two acyl substituents, acetate and glycerate, are located on the 3-linked D-glucose. On average there is one glycerate per repeat unit and one acetate per every two repeats (Kuo and Mort 1986). Alkaline hydrolysis results in complete deacylation and yields the low acyl form.

X-ray diffractions measurements determined that the ordered structure of gellan gum in the solid state is a double helix composed of two left-handed, 3-fold helical chains (Chandrasekaran and others 1988a; Chandrasekaran and others 1988b). The gellan chain derives stability through three intramolecular hydrogen-bonds per tetrasaccharide unit, and the double-helix is stabilized by three inter-chain hydrogen bonds (Chandrasekaran and others 1988a). Optical rotation and light scattering techniques have established that gellan gum undergoes a conformational transition from the disordered state (two single coils) at high temperature to the ordered state (one double helix) at low temperature (Grasdalen and Smidsrød 1987; Dentini and others 1988; Milas and others 1990; Takahashi and others 2004). The transition temperature between the two states is $\sim 30$ $35^{\circ} \mathrm{C}$ (Milas and others 1990; Nishinari and others 1996). The gellan molecule behaves as a stiff chain in both the disordered and order state; however, the stiffness is substantially greater in the ordered double helix state (Dentini and others 1988; Milas and others 1990; Okamoto and others 1993; Takahashi and others 2004). High chain stiffness results in the 
development of high viscosity at low concentrations in both states. The intrinsic viscosity of the ordered helical structure is larger due to an increase of the stiffness of the molecule (Milas and others 1990).

The $\mathrm{M}_{\mathrm{w}}$ of gellan gum is dependent on structural confirmation and is reported to double transitioning from the disordered to ordered state. Light scattering experiments determined gellan gum in the disordered state $\left(36^{\circ} \mathrm{C}\right)$ to have a $\mathrm{M}_{\mathrm{w}}$ of $250 \mathrm{kDa}$ and in the ordered state $\left(24^{\circ} \mathrm{C}\right)$ to have a $\mathrm{M}_{\mathrm{w}}$ of $490 \mathrm{kDa}$ (Milas and others 1990). These results confirm a previous light scattering measurement that determined gellan gum in the ordered helical state $\left(25^{\circ} \mathrm{C}\right)$ to have a $\mathrm{M}_{\mathrm{w}}$ of $434 \mathrm{kDa}$ and a hydrodynamic radius of 52.2 nm (Dentini and others 1988). However, light scattering measurements in a subsequent study determined the ordered state $\left(25^{\circ} \mathrm{C}\right)$ to have a $\mathrm{M}_{\mathrm{w}}$ of $238 \mathrm{kDa}$ and a hydrodynamic radius of $30.9 \mathrm{~nm}$ (Okamoto and others 1993).

Gellan gum is commonly used as a gelling and structuring agent and also in the formation of films and coatings. Functionality of gellan gum depends on the degree of acetylation and the ions present. The high acyl form produces soft, elastic, non-brittle, thermoreversible gels, while the low acyl form produces firm, non-elastic, brittle, nonthermoreversible gels (Kang and others 1982). Gelation is attributed to the double helix formation occurring as a hot solution cools and the association of helices enhanced by the presence of metallic cations (Milas and others 1990). Gelation temperature increases with increasing gellan gum concentration from $33^{\circ} \mathrm{C}$ for a $1 \%$ solution up to $55^{\circ} \mathrm{C}$ for a $2.5 \%$ solution (Dai and others 2008). Gelation is dependent upon ionic strength and the identity of the cation. In the ordered state, even at an infinite dilution, the stiff double-helical 
molecule tends to form aggregates, going to a gel with an ionic selectivity in the order of effectiveness $\mathrm{K}^{+}>\mathrm{Na}^{+}>\mathrm{Li}^{+}$(Grasdalen and Smidsrød 1987; Milas and others 1990). The differences in gel strengths among the divalent salts $\left(\mathrm{Mg}^{2+}, \mathrm{Ca}^{2+}, \mathrm{Sr}^{+2}, \mathrm{Ba}^{2+}\right)$ are not distinguishable (Grasdalen and Smidsrød 1987). The setting temperature for gellan gum gels has been reported to vary considerably in the presence of different salts (Grasdalen and Smidsrød 1987). Maximum gel strength was achieved at a higher temperature and at a much lower concentration of divalent cations than with monovalent cations or without salt (Moritaka and others 1991; Lee and others 2003). Crosslinking formation in double helices with monovalent cations was much less effective than with divalent cations because monovalent cations helped crosslinking indirectly with water molecules while divalent cations establish direct polyanion-cation-polyanion interactions (Chandrasekaran and others 1988b). A storage stability study on gellan gum gels reported that the water content and texture properties of the gels did not significantly change after several months of storage, but that the freeze-thaw stability of the gels was poor (Mao and others 2001). Dispersions of $1 \%$ gellan gum in water at $25^{\circ} \mathrm{C}$ showed shear thinning behavior over the shear rate range 0-500 s ${ }^{-1}$ (Yáñez-Ferández and others 2008).

\subsubsection{Algal}

Several species of seaweed contain naturally occurring polysaccharides which fill the cellulose structure within the plant. Sulfated galactans, such as agar and carrageenans are found in red seaweeds (Rhodophyceae), and alginates are found in brown seaweeds (Phaeophyceae). 


\subsubsection{Carrageenan}

Carrageenans belong to the family of hydrophilic linear sulfated galactans extracted from different species of marine red algae of the class Rhodophyceae. The three major carrageenan types are iota, kappa, and lambda. Carrageenans are composed of repeating D-galactose and anhydro-D-galactose units and possess different degrees of sulfation which leads to varying degrees of negative charge and solubility in water. The differences in carrageenan composition produce a wide spectrum of rheological properties including gelation, stabilization, suspension and thickening, which are utilized a large number of food, pharmaceutical, and cosmetic products.

\subsection{Kappa-Carrageenan}

Kappa-carrageenan is a linear sulfated homopolysaccharide comprised of repeating D-galactose and anhydro-D-galactose units that is obtained by extraction with water or alkaline water from certain species of red seaweeds. Kappa-carrageenan possesses the lowest relative degree of sulfate substitution amongst the carrageenans, having one sulfate ester group per disaccharide unit and is therefore the least negativelycharged and the least soluble in cold water. Steady shear viscosity and dynamic oscillatory measurements during temperature ramps indicate that at ambient temperature the polymer is present as highly swollen but still discrete particles in water (Ramakrishnan and Prud'homme 2000). 
X-ray diffractions measurements determined that the ordered structure of kappacarrageenan in the solid state is a double helix composed of two right-handed, 3 -fold helical chains with one intermolecular hydrogen bond per disaccharide unit (Anderson and others 1969; Millane and others 1988). At high temperatures, the polymer is in a disordered state and is present as random coils due to dissolution of the particles by transformation of the helices into coils and weakening of the ion-mediated bonding forces (Ramakrishnan and Prud'homme 2000). The conformational transition from a disordered (random coils) to an ordered state (double helices) has been detected at high concentrations of appropriate salts and lower temperatures (Norton and others 1983). The coil-helix transformation onset temperature upon cooling occurs at $23-24^{\circ} \mathrm{C}$ (Ekström and Kuivinen 1983; Cardoso and Sabadini 2010). Hydrodynamic volume of the chains increases upon conformational ordering as a result of chain stiffening (Hjerde and others 1999). The intrinsic viscosity of the ordered helical structure is larger due to an increase of the stiffness of the molecule (Smidsrød and Grasdalen 1984; Slootmaekers and others 1988).

The $\mathrm{M}_{\mathrm{w}}$ of kappa-carrageenan is dependent on structural confirmation and is reported to double transitioning from the disordered to ordered state (Hjerde and others 1999). Multi-angle laser light scattering determined kappa-carrageenan in the disordered state to have a $\mathrm{M}_{\mathrm{w}}$ of $324-327 \mathrm{kDa}\left(25^{\circ} \mathrm{C}\right.$ in $\left.100 \mathrm{mM} \mathrm{NaNO}_{3}\right)$ and $309 \mathrm{kDa}\left(50^{\circ} \mathrm{C}\right.$ in $100 \mathrm{mM} \mathrm{NaI})$ and in the ordered state to have a $\mathrm{M}_{\mathrm{w}}$ of $468-675 \mathrm{kDa}\left(25^{\circ} \mathrm{C}\right.$ in $100 \mathrm{mM}$ NaI) (Viebke and others 1995; Viebke and Williams 2000). These results are in agreement with studies that determined kappa-carrageenan in the disordered state to have 
a $\mathrm{M}_{\mathrm{w}}$ of $331-390 \mathrm{kDa}\left(25^{\circ} \mathrm{C}\right.$ in $\left.100 \mathrm{mM} \mathrm{NaCl}\right)$ (Slootmaekers and others 1991 ; Kalitnik and others 2013).

Kappa-carrageenan is extensively used in the food industry as a gelling, thickening, and stabilizing agent. Gelation of kappa-carrageenan involves two separate and successive steps; coil-to-helix transition upon cooling and subsequent cationdependent aggregation between helices (Anderson and others 1969; Viebke and others 1994; Borgström and others 1996; Yuguchi and others 2002). The element of crosslinking in the gel of kappa-carrageenan is associated with the formation of doublehelices and further aggregation into junction zones (Cardoso and Sabadini 2010). Gelation is thermoreversible and is dependent upon ionic strength and the identity of the cation. The nature of monovalent cations has a strong influence on gelation temperature in the order of effectiveness $\mathrm{Rb}^{+}, \mathrm{Cs}^{+}, \mathrm{K}^{+}>\mathrm{Na}^{+}>\mathrm{Li}^{+}$(Rochas and Rinaudo 1980), while the influence of divalent cations $\left(\mathrm{Mg}^{2+}, \mathrm{Ca}^{2+}, \mathrm{Sr}^{+2}, \mathrm{Ba}^{2+}\right)$ is slight with small differences in effectiveness among the divalent salts (Rochas and Rinaudo 1980). Atomic force microscopy showed that the addition of $\mathrm{K}^{+}$or $\mathrm{Ca}^{2+}$ formed localized networks through side-by-side interhelical aggregation, and that the aggregation was more apparent with the addition of $\mathrm{K}^{+}$(Funami and others 2007). Dispersions of 1\% kappa-carrageenan in water at $25^{\circ} \mathrm{C}$ showed shear thinning behavior over the shear rate range $0.01-100 \mathrm{~s}^{-1}$ (Ramakrishnan and Prud'homme 2000).

\subsubsection{Tree Gum Exudates}


Exudate gums are complex polysaccharides that are produced by several plants spontaneously or in response to adverse conditions or mechanical or microbial injury as natural defense mechanisms (Aspinall 1967; Rana and others 2011). A physical barrier is formed as the sticky gum oozes from the trunks and branches of the plant and dries to a hard glass. Gum exudates are the most complex of the polysaccharide group of natural products and are often highly branched (Anderson 1978). Gum tragacanth, being composed of two polysaccharide components of entirely different structural type, provides an example of one form of polymer heterogeneity recognized amongst the polysaccharide constituents of the exudate gums. The polysaccharides of gum exudates are composed of mostly arabinose and galactose, together with varying proportions of rhamnose, D-glucuronic acid (or its 4-methyl ether) and/or D-galacturonic acid. A number of gum exudates are of high commercial importance, including gum ghatti, gum tragacanth, gum karaya, and gum arabic, which is oldest and best known of all natural gums.

Plant gums can be categorized into three groups based on common structural units, galactans, glucuronomannans, and galacturonans or rhamnogalacturonans. The galactan group of exudate gums contains polysaccharides with a branched core of $\beta$-Dgalactopyranose residues. Gum arabic was the first gum of this type to be characterized. These polysaccharides vary to some extent in the degree of branching in the galactan core and also differ in the sites of attachment of the peripheral L-arabinose and L-rhamnose residues and in the nature of the more complex substituted L-arabinose units (Aspinall 1967). Gum arabic and related exudate gums including tragacanthin, a component of gum 
tragacanth, can also be classified as arabinogalactans, which contain $2-10 \%$ covalently attached protein rich in hydroxyproline and serine (Fincher and others 1983). Structural models for AGPs suggest a compact molecule consisting of a protein core to which highly branched polysaccharide chains are attached predominantly through linkage to hydroxyproline (Fincher and others 1983; Sims and Furneaux 2003).

The glucuronomannan group contains polysaccharides with interior chains of Dglucuronic acid and D-mannose residues and side-chains composed of varying units. Gum ghatti is classified within this group.

The galacturonan or rhamnogalacturonan group consists of three sub-groups with partial structural overlap. Polysaccharides within this group contain residues of Dgalacturonic acid located mainly in the interior chains and D-glucuronic acid located mainly as terminal units in side-chains attached to a variety of different sugar residues (Aspinall 1967). The first and second sub-groups within galacturonan contain partially acetylated polysaccharides with interior chains of D-glucuronic acid and L-rhamnose, while the third sub-group contains polysaccharides based on essentially linear chains of D-galacturonic acid residues. Karaya gum is classified within the first sub-group of galacturonan and tragacanthic acid, the main polysaccharide component of gum tragacanth, is classified within the third sub-group of galacturonan.

\subsubsection{Gum Arabic}

Gum arabic, also known as gum acacia, is a dried exudation obtained from Acacia senegal or related species of Acacia (family Leguminosae) and is a complex, highly 
branched, anionic polysaccharide. Acacia senegal grown principally in Sudan is the most important source of commercial gum arabic and has been the subject of numerous detailed investigations. Variation in sugar composition, nitrogen content, and molecular mass between gum arabic samples has been documented (Anderson 1978). However, wide angle X-ray scattering analysis investigating the macroscopic structure of two different species of gum arabic revealed that the samples were identical in crystalline structure (Cozic and others 2009). The monosaccharide composition, protein content, amino acid profile and optical rotation of Acacia senegal gum samples from trees of varying age and regions of Sudan were found to be similar; however, the intrinsic viscosity, average molecular mass, and hydrodynamic radius were found to vary significantly (Idris and others 1998). Gum arabic is a proteinaceous polysaccharide with a protein content ranging from 1.5-3\% (Anderson and others 1985b; Randall and others 1989). Chemical analysis indicates that the gum consists mainly of a highly complex polysaccharide of a branched D-galactose backbone with branches linked with Larabinose, L-rhamnose and D-glucuronic acid in ramified side-chains (Anderson and others 1966b). This branching that occurs within the side-chains results in a highly compact, globular molecule and explains why gum arabic solutions become viscous only at high concentrations. L-rhamnose residues mainly occur as non-reducing end groups glycosidically linked to D-glucuronic acid (Aspinall and others 1963). Minor amounts of doubly-branched D-galactose are apparent through NMR spectroscopy of fractionated gum arabic (Williams and others 1990). Gum arabic is heteropolymolecular, consisting of 
molecules that differ in sugar composition, mode of linkage and branching of monomer units, and in molecular mass (Anderson and Stoddart 1966).

Investigations have demonstrated that gum arabic is a complex material consisting of a wide range of carbohydrate and glycoprotein/proteoglycan molecular constituents which contain similar proportions of sugars and share common structural features (Williams and others 1990; Osman and others 1995). Using hydrophobic affinity chromatography, gum arabic was separated into three fractions (Randall and others 1989; Osman and others 1993; Ray and others 1995). These fractions were referred to as an arabinogalactan (AG) fraction (88.4\% of total gum weight, $20.1 \%$ of total protein), an arabinogalactan-protein complex (AGP) fraction (10.4\% of total gum weight, $49.5 \%$ of total protein), and a glycoprotein (GP) fraction (1.2\% of total gum weight, $24.2 \%$ of total protein) (Randall and others 1989). X-ray and neutron scattering measurements determined the overall shape of gum arabic to be composed of many spheroidal structures of the major component, AG, which is a highly branched charged polysaccharide, interlaced with a small amount of large coils of AGP (Dror and others 2006). The large coils were rationalized by the high molecular weight of AGP, combined with the charged branched arabinogalactan side chains of the protein backbone which would inhibit a compact conformation (Dror and others 2006). Interactions of the fractions with an artificial carbohydrate antigen (Yariv reagent) indicated that all three fractions contained arabinogalactan proteins (AGPs) (Osman and others 1993).

The arabinogalactan (AG) fraction has a highly branched, block-type structure. It was determined to have an 'equivalent sphere' hydrodynamic radius of $9.2 \mathrm{~nm}$ by photon 
correlation spectroscopy, which is very small for a molecular mass of $2.79 \times 10^{5}$ dalton (Randall and others 1989). The small hydrodynamic volume of the compact and branched AG fraction explains why gum arabic solutions are characterized by a low viscosity. Atomic force microscopy (AFM) determined the length of individual polymer chains to range from 90-270nm, which is reasonable but short in comparison to the estimated molecular weight (Ikeda and others 2005). It was theorized that only a population of short chains could be visualized using the AFM method and/or that the chain length per unit mass is relatively short due to highly branched structures (Ikeda and others 2005). Smallangle neutron scattering and microscopy provided a model suggesting AG was an oblate ellipsoid with an open and highly branched internal structure, the central part forming a kind of intricate network, with a thickness of $1.4 \mathrm{~nm}$ and a diameter of $20 \mathrm{~nm}$ (Sanchez and others 2008).Each AG molecule contains < 10 amino acid groups, which have been determined to play an insignificant role in the overall structure (Randall and others 1989).

The arabinogalactan-protein complex (AGP) fraction was determined to have an 'equivalent sphere' hydrodynamic radius of $22.8 \mathrm{~nm}$ by photon correlation spectroscopy, which indicates a very compact structure for a molecular mass of $1.45 \times 10^{6}$ dalton (Randall and others 1989). A wattle blossom model has been proposed for AGP (Fincher and others 1983) and supported by many others (Duvallet 1989; Idris and others 1998; Picton and others 2000). The wattle blossom model was shown to consist of varying numbers of large arabinogalactan side-chains with a molecular weight of $2.0 \times 10^{5}$ dalton are individually attached to a common core polypeptide chain (Connolly and others 1987; Connolly and others 1988). In support of the wattle blossom model, it was determined 
that each AGP molecule consists of five carbohydrate blocks of molecular mass $2.8 \times 10^{5}$ dalton linked together by amino acid residues to form a very compact structure (Randall and others 1989). An alternative model describing the AGP as a twisted hairy rope was proposed (Qi and others 1991), but is not well supported in comparison to the wattle blossom model. The twisted hairy rope modeled was validated when it was concluded that gum arabic glycoprotein possessed a highly repetitive polypeptide with as many as five side chains of forty sugar units which are much smaller than what was proposed with the wattle blossom model (Goodrum and others 2000). Each AGP molecule contains up to 1,600 amino acid residues located along the periphery in the form of chains that enable the molecule to adsorb onto hydrophobic surfaces and explain its ability to sterically stabilize emulsions and dispersions (Randall and others 1989). AGP has been shown to strongly influence the behavior of the whole gum (Fauconnier and others 2000) and to dominate emulsification properties (Castellani and others 2010).

The glycoprotein (GP) fraction was determined to have a molecular weight of 2.5 x $10^{5}$ by semi-preparative gel permeation chromatography (Randall and others 1989).

Using ion-exchange chromatography, gum arabic was separated into five or six polydisperse fractions (Osman and others 1995). Ion-exchange chromatography separates molecules according to proportion of anionic groups rather than protein content as in hydrophobic affinity chromatography. The different means of separation employed by the two techniques explains the dramatic difference in fractions and demonstrates the molecular complexity of gum arabic. The carbohydrate composition of all fractions remained relatively constant with each containing similar proportions of galactose, 
arabinose, rhamnose and glucuronic acid; however, the protein content varied slightly (Osman and others 1995). Interactions of the fractions with Yariv reagent indicated that all fractions contained AGPs (Osman and others 1995).

Molecular weights of gum arabic show wide variations which can be primarily attributed to the heterogeneity of the gum and the method of determination. Numberaverage molecular weight $\left(\mathrm{M}_{\mathrm{n}}\right)$ was determined to be $1.9 \times 10^{5}$ (Duvallet and others 1989) and between $1.6 \times 10^{5}$ and $4.5 \times 10^{5}$ by gel permeation chromatography/multiangle laser light scattering (Idris and others 1998). Weight-average molecular weights $\left(\mathrm{M}_{\mathrm{w}}\right)$ of gum arabic were determined to be $5.6 \times 10^{5}$ dalton by steric-exclusion chromatography (Churms and others 1983), and $4.6 \times 10^{5}, 5.8 \times 10^{5}$, and $7.2 \times 10^{5}$ dalton by lightscattering experiments (Anderson and others 1966a; Duvallet and others 1989; Randall and others 1989). The variation in the molecular weight values as determined by different methods and behavior of the gum on ultracentrifugation is indicative of a broad distribution of molecular weights among the polysaccharide components of the gum (Churms and others 1983). This polymolecularity has been widely noted (Anderson and Stoddart 1966; Churms and others 1983; Osman and others 1995; Ray and others 1995). Comparison of $\mathrm{M}_{\mathrm{n}}$ and $\mathrm{M}_{\mathrm{w}}$ on the same sample before and after proteolysis treatment was done to further understand the meaning of molecular weight measurements of gum arabic. $M_{w}$ changed from $7.2 \times 10^{5}$ to $1.8 \times 10^{5}$ after pronase treatment, while $M_{n}$ remained fairly constant (1.9-1.8 x10 $)$ (Duvallet and others 1989). It was suggested that since after treatment the $M_{w}$ and $M_{n}$ values were the same, that $M_{n}$ could be considered as an intrinsic property while $\mathrm{M}_{\mathrm{w}}$ reflects the heterogeneity restricted to the protein core which 
links some homogeneous and well defined chains and some of polydispersity (Duvallet and others 1989).

The amino acid profile for whole gum arabic was found to contain high proportions of hydroxyproline and serine (Anderson and others 1985b; Randall and others 1989; Osman and others 1995). The AG and AGP fractions had an amino acid profile similar to the whole gum; however, the GP fraction had a very different profile, with aspartic acid, phenylalanine, serine, glutamic acid, glycine, valine and leucine being major amino acids (Randall and others 1989; Ray and others 1995). Molecular-sieve chromatography experiments have indicated that high molecular weight protein is involved, not short-chain polypeptides, and that frequently more than one component appear to be present (Anderson and others 1972).

Gum arabic is used in confectionary, in the clarification of wines, as an adhesive, and as a stabilizer or emulsifier in a wide variety of food applications (Anderson 1978). It is utilized in large quantities by the soft drinks industry for the stabilization of emulsions or flavor oils (Dickinson and others 1989). The excellent emulsifying properties result from a unique combination of many molecular units differing in size and composition. Evaluation of the AG and AGP fractions in orange oil emulsions showed that the AG fraction made a poor emulsion while the protein rich AGP fraction made an excellent emulsion (Ray and others 1995). Fractionation studies showed that in general, emulsion stability increased with increasing molecular weight and protein content, and that a mixture of low and high molecular fractions made a better emulsion than either fraction alone (Ray and others 1995). The differences in emulsion stability were attributed to 
nonelectrostatic factors (Ray and others 1995). The ability of gum arabic to lower the interfacial tension at the oil-water interface during the early stages of adsorption correlates well with its emulsifying capacity and emulsion stabilizing properties (Dickinson and others 1988; Castellani and others 2010). The emulsifying properties of gum arabic are dependent on the total protein/polypeptide content, on the distribution of the protein/peptide between the low- and high-molecular-weight fractions, and on the molecular accessibility of the protein/peptide for adsorption (Dickinson and others 1988).

Gum arabic does not act as a viscosity-enhancing thickener like most polysaccharide gums (e.g. xanthan), but rather as a surface-active agent which forms a thick, sterically stabilizing, macromolecular layer around the emulsion droplets (Dickinson and others 1989). The quantity of gum arabic used to stabilize food emulsions is 5-10 times larger than that for proteinaceous emulsifiers such as casein because only a portion of the gum is adsorbed at the interfaces. It has been shown that a stable $20 \%$ orange oil emulsion required gum arabic concentrations of $>12 \%$ and that only $1-2 \%$ of the gum, predominately the AGP fraction, actually adsorbed at the oil-water interface (Randall and others 1988). It was theorized that the hydrophobic polypeptide chain adsorbed at the oil droplet surface, anchoring the molecule, while the hydrophilic carbohydrate blocks attached to the chain protruded out into the aqueous phase and gave rise to steric stabilization (Randall and others 1988).

Rheological properties of gum arabic solutions have been well studied. Newtonian behavior was observed across a wide range of concentrations and at high shear rates; however, a pronounced shear thinning was observed in low shear rate ranges 
(Li and others 2009). Dispersions at concentrations between 3 and 32\% showed shearthinning flow behavior at shear rates $<10 \mathrm{~s}^{-1}$ (Sanchez and others 2002). An equilibrium association of gum arabic molecules was suggested to account for the shear-thinning behavior and departure from Newtonian behavior (Li and others 2009). Over the shear

rate range $1-10 \mathrm{~s}^{-1}$, dispersions with concentrations between 10 and $25 \%$ exhibited more pronounced shear-thinning behavior than dispersions with concentrations in the range 30-50\% (Mothé and Rao 1999). This behavior of gum arabic dispersions was similarly attributed to the presence of micro-aggregates within the dispersion (Mothé and Rao 1999). Further investigation on the rheological behavior showed thixotropy for gum arabic solution at low shear rates due to the presence of molecular associations ( $\mathrm{Li}$ and others 2011). Gum arabic solutions demonstrated a progressive increase in the apparent viscosity dependence of concentration and insignificant change in viscosity after a mild heat treatment of $80^{\circ} \mathrm{C}$ for 30 min (Mothé and Rao 1999).

\subsubsection{Gum Karaya}

Gum karaya is a dried exudation obtained from Sterculia (family Sterculiaceae) and is a complex, highly branched, partially acetylated, anionic polysaccharide. It contains up to $1 \%$ of a proteinaceous component (Anderson and others 1985c). Acid hydrolysis yields sugars of D-galacturonic acid, D-galactose, L-rhamnose, and small proportions of D-glucuronic acid. Total uronic acid residue content in the gum can be up to $35-40 \%$. Proportions within the primary structure have been shown to differ according to the quality, type of gum and origin (Aspinall and Fraser 1965; Aspinall and Nasir-ud- 
din 1965; Aspinall and others 1965; Aspinall and Sanderson 1970a; Aspinall and Sanderson 1970b). Comparison of Sterculia striata to Sterculia urens showed a similar monosaccharide composition except for the presence of xylose in $S$ striata that was not identified in S urens (Brito and others 2004). Despite the reported variations, Sterculia exudates have remarkably similar proportions of their constituent sugars and other analytical polysaccharide parameters unlike gum arabic and gum tragacanth which show tremendous variation. The molecular weight of gum karaya was determined to be between $9.5 \times 10^{6}$ (Kubal and Gralén 1948) and $16 \times 10^{6}$ dalton (Le Cerf and others 1990). The dimensions of the gum are $2,750 \AA$ by $86 \AA$, which indicates that the molecule is very tightly packed (Kubal and Gralén 1948). In comparison to gum tragacanth, gum karaya possesses a molecular mass that is 11-19 times as large in a space that is only 3 times as large.

Structural studies (Hirst and Dunstan 1953; Aspinall and Sanderson 1970b; Raymond and Nagel 1973) indicate that the macromolecules are cylindrical in shape and highly branched, with interior D-galacturonic acid and L-rhamnose units as the main chains (Anderson and others 1985c). This elongated framework provides an assortment of ionizable acidic groups interspersed with hydrophobic regions provided by the methyl groups of the rhamnose units and of the acetyl groups in the native gum. Gum karaya has a higher rhamnose content than other commercial exudate gums. Most of the rhamnose is in the main chain of the gum, whereas more of the galactose residues exist as branches (Aspinall and Nasir-ud-din 1965; Raymond and Nagel 1973). It contains relatively rigid ordered domains of high intramolecular attraction and more flexible less associated 
domains due to the order-destroying effect of bulky side chains that readily entrain water molecules (Silva and others 2003). Side chains are attached by linkage of D-galactose or by linkage of D-glucuronic acid to the galacturonic acid of the main chain. Additionally, half of the rhamnose residues of the main chain are linked to D-galactose units.

More than one type of chain structure is present in the molecule (Aspinall and Sanderson 1970b; Raymond and Nagel 1973). However, the number, the chemical composition, and the arrangement of side-chains are disputed due to the complexity of the gum. Degradation of carboxy-reduced Sterculia urens gum determined there be two chain structures present as alternating blocks in a single chain (Aspinall and Sanderson 1970b). Degradation of Sterculia urens gum by a fungal isolate, Cephalosporium sp. indicated that the gum contained at least three different types of chains that could be arranged in a number of ways; including, repeating units in a single chain or two parallel chains bridged at intervals by the third chain (Raymond and Nagel 1973). It is clear that the gum possesses a highly branched structure, with some residues being triply-linked in the gum (Hirst and Dunstan 1953). According to the three chain model, one chain (50\% of the total polysaccharide) contained repeating units of four galacturonic acid residues containing D-galactose branches and having an L-rhamnose residue at the reducing end of the unit (Raymond and Nagel 1973). A second chain (17\% of the polysaccharide) contained $50 \%$ galacturonic acid, $40 \%$ rhamnose, and $10 \%$ galactose by weight as well as an oligorhamnan chain containing D-galacturonic acid branch-residues interrupted occasionally by a D-galactose residue (Raymond and Nagel 1973). Chain II may have had at least 50 monosaccharide residues (Raymond and Nagel 1973). A third chain (33\% 
of the polysaccharide) contained the entirety of D-Glucuronic acid found within gum karaya and was determined to be a complex chain in which no two consecutive units or linkages were alike (Raymond and Nagel 1973).

The amino acid profile of the proteinaceous component of gum karaya is high in aspartic acid, valine, leucine, glutamic acid, and proline (Anderson and others 1985c). Gas chromatography-mass spectrometry (GC-MS) analysis re-confirmed the presence of aspartic acid and glutamic acid as the major amino acids but did not detect alanine or valine (Vinod and others 2010). The considerable differences between the reported amino acid compositions of gums indicate variety within gum karaya even though there is little difference in terms of polysaccharide composition. The amino acid profile for gum karaya differs greatly from that for gum arabic, for which the major amino acids are hydroxyproline and serine (Anderson and others 1985b) and guar gum, for which the major amino acids are glycine, glutamic acid and aspartic acid (Anderson and others 1985d). Lipid content of gum karaya was determined by GC-MS analysis to be $2 \%$ by mass and was theorized as being responsible for the emulsifying property of the gum (Vinod and others 2010).

Emulsifying, stabilizing and thickening properties make gum karaya commercially important to the food and pharmaceutical industry. It is polydisperse and the native gum nodules swell in water but do not dissolve in it, probably as a consequence of the presence of acetyl groups (Le Cerf and others 1990). The tertiary structure of gum karaya in colloidal suspension is hypothesized to behave as matted coils, with the solvent immobilized within the coils of the molecules (Kubal and Gralén 1948). 
Gum karaya contains many acid groups which attract and immobilize large amounts of water (Kubal and Gralén 1948). A 1\% solution has a pH of 4.5-5.2 and the viscosity of solutions decrease upon the addition of acid or alkali. The native acetylated gum karaya assumes a rather compact and branched conformation in aqueous solution; in contrast, the fully deacetylated gum karaya assumes a more expanded and less branched conformation and behaves as a random coil (Le Cerf and others 1990). Gum karaya forms only seemingly homogeneous solutions because from each particle there remains an insoluble gelatinous residue suspended in the solution (Kubal and Gralén 1948). Viscosity of gum karaya solutions increase rapidly with concentration. Solutions at concentrations greater than $1 \%$ flow very slowly; those greater than $2 \%$ form opaque pastes; and those of $5 \%$ are solid gels (Kubal and Gralén 1948).

Gels can be classified either as strong or weak on the basis of their dynamic viscous modulus (G') / elastic modulus (G') ratio. The G'/G" ratio of a true gel, whose intermolecular junctions have a high binding energy, is higher than 3 (Lapasin and others 1995). Dynamic rheological analysis for gum karaya aqueous solutions showed that true gels were formed at 2-5\% concentration (Brito and others 2005). Gelation could be due to the formation of intermolecular junction zones, involving ionic interaction between homogalacturonic segments of different chains and calcium ions giving an 'egg-box model', and hydrogen bonding between rhamnose segments in the hydrophobic areas (Silvia and others 2003). Ionic interactions could also occur between two or more galacturonic acid residues on different main chains or glucuronic acid residues in 
branched or non-regular chain segments (Silvia and others 2003). It is suggested that the acetyl groups contribute to the stability of the junction zones (Silvia and others 2003).

\subsubsection{Gum Tragacanth}

Gum tragacanth is a dried gummy exudation obtained from Astragalus (family Leguminosae) and is a highly branched, anionic carbohydrate polymer, representing a heterogeneous chemical system as complex as any natural product known. It is regarded as a proteinaceous polysaccharide, with a protein content of 3-4\% (Anderson and Bridgeman 1985). Acid hydrolysis yields sugars of L-arabinose, D-xylose, L-fucose, Dgalacturonic acid, D-galactose, and a small amount of L-rhamnose. The measurement of its high molecular weight is difficult because the gum is incompletely soluble in water (Anderson and others 1985a). The molecular weight of gum tragacanth, using Svedberg's method and formula was calculated to be $8.4 \times 10^{4}$ dalton and it was determined to have an elongated shape of 4,500 ̊̊ by $19 \AA$ (Gralén and Karrholm 1950). Gum tragacanth has a much more extended shape than gum karaya and its molecules are smaller, but they give rise to a higher viscosity which is likely due shorter side chains than those of gum karaya (Gralén and Karrholm 1950).

Gum tragacanth consists of two major fractions: a water-swellable fraction termed tragacanthic acid or bassorin and a water-soluble fraction termed tragacanthin.

Tragacanthic acid is based on essentially linear chains of 1,4-linked D-galacturonic acid residues, with the majority of D-galacturonic acid residues carrying xylose-containing side-chains (Aspinall and Baillie 1963a). Three types of side-chain have been recognized, 
namely single D-xylose residues, and disaccharide units of L-fucose linked to D-xylose and D-galactose linked to D-xylose (Aspinall and Baillie 1963a). Tragacanthin is a highly branched arabinogalactan, with a structure based on a core of adjoining D-galactose residues to which highly ramified exterior chains of L-arabinose chains are attached (Aspinall and Baillie 1963b). More advanced analyses showed the structure of the arabinogalactan to be even more complex than previously determined, with core structures containing arabinose and galactose units, as well as known attached chains of arabinose units (Tischer and others 2002). It has been reported that $1 \%$ tragacanthic acid (water-swellable fraction) dispersion at $25^{\circ} \mathrm{C}$ shows a high-viscosity gel-like structure similar to that obtained for a weak gel system such as xanthan gum, while a tragacanthin (water-soluble fraction) solution behaves as a semi-dilute to concentrated solution of entangled, random coil polymers (Mohammadifar and others 2006). Both fractions contain small amounts of proteinaceous material and methoxyl groups, the latter present in higher amounts in the water-soluble fraction (Anderson and Bridgeman 1985). It is not yet understood if the two polysaccharides are in a physical mixture or chemically bonded to each other. Analysis of the shear stress-shear rate relationship of gum tragacanth may indicate that the gum is a mixture of two different polysaccharide fractions which could separate easily in aqueous media (Balaghi and others 2010).

The amino acid profile of the proteinaceous component of gum tragacanth is high in hydroxyproline, with other major amino acids being proline, serine, and valine (Anderson and others 1985a). Very high proportions of hydroxyproline have also been reported in samples of gum arabic (Acacia Senegal) (Anderson and others 1985b). In 
contrast, gum karaya (Sterculia spp.) does not contain high proportions of hydroxyproline (Anderson and others 1985c). The differences in hydroxyproline content between tree gum exudates is explained by gum tragacanth and gum arabic being members of the family Leguminosae while gum karaya is a member of the family Sterculiaceae. Hydroxyproline is a major functionality determinant due to its involvement in glycosidic linkages to arabinose, its role in the stabilization of protein triple helical structures, and its tendency for forming connecting sequences in core proteins associated with arabinogalactans.

Commercial gum tragacanth is a highly variable product. The gum obtained from different Astragalus species shows extensive variation in sugar composition, methoxyl content, relative proportion of soluble and insoluble components, and amino acid composition (Anderson and Bridgeman 1985). The ratio of soluble to insoluble components is related to the swelling power of different gum particles and may cause the variation in particle size distribution of different species of gum dispersions (Balaghi and others 2010). Analytical characterization of seven Iranian commercial gum tragacanth samples showed the variations between samples are most significant for the nitrogen content (range $0.08-0.52 \%$ ), methoxyl content $(2.7-4.8 \%$ ), and the relative proportions of each of the sugars present, in particular, the ratio of arabinose to fucose varies greatly from 10:34 to 49:8 (Anderson and Bridgeman 1988). Also, commercial samples obtained from one particular species show larger differences in chemical composition than those expected due to seasonal and geographical variations (Anderson and Bridgeman 1985; Verbeken and others 2003). These variations in chemical composition reflect changes in 
the fine structure of the gum molecules and are adequate to explain the differences in functionality shown by commercial samples, including the great variability in the viscosity. In comparison with the lower viscosity exudates, the higher viscosity gums have high galacturonic acid, xylose, fucose and methoxyl contents and low arabinose and nitrogen contents (Anderson and Grant 1989).

Gum tragacanth has been used as a stabilizer, emulsifier and thickener in food, pharmaceutical, and cosmetic industries. It is one of the most efficient natural oil-inwater emulsifiers known, particularly for acidic systems (Anderson and Bridgeman 1988). It is very effective in lowering the interfacial tension, even at low concentrations, and simultaneously acts as a thickener of the continuous phase of the emulsion, preventing flocculation and coalescence of the dispersed oil droplets (Verbeken and others 2003). Gum tragacanth is an effective stabilizer of colloidal suspensions at very low concentrations by means of steric repulsion force (Yokoyama and others 1988). A $1 \%$ solution has a $\mathrm{pH}$ of $5-6$, but the viscosity remains stable over a broad $\mathrm{pH}$ range of 210. The $\mathrm{pK}_{\mathrm{a}}$ of gum tragacanth was determined to be 3.0 (Yokoyama and others 1988). Gum tragacanth is polydisperse and swells rapidly in either cold or hot water to form highly viscous, stable solutions at a low concentration that are liquids and not gels. The viscosity is extremely high but the solutions always behave as liquids, not as solid gels, even at a concentration of $3.7 \%$, which is essential for the practical use of gum tragacanth in pourable applications or where a specific mouthfeel is necessary (Gralén and Karrholm 1950). Oscillatory shear data for gum tragacanth at $25^{\circ} \mathrm{C}$ indicate a solution of entangled, flexible coil polymers (Harry-O'Kuru and others 1999). These properties as well as 
adhesive capabilities depend on the chemical composition and shape of the gum molecules.

\subsubsection{Seeds}

Several of the most commercially important seed gums are guar gum, locust bean gum, and tara gum. Seed gums are classified as galactomannans and are mostly obtained from the endosperms of leguminous plants. In aqueous solutions, galactomannans predominantly exist in a random-coil conformation (Dea and others 1977). Galactomannans are neutral heteropolysaccharides generally composed of a D-mannose main chains to which D-galactose units are attached. The mannose to galactose ratio differs amongst the gums and typically ranges from 1.1 to 5.0. Side chain content and distribution influence the solution properties of galactomannans (Dea and others 1977). Rheological properties of galactomannans in aqueous solutions are dependent upon shear rate, temperature, $\mathrm{pH}$, and concentration (Morris and others 1981). Galactomannans are used extensively in the food industry as thickening and stabilizing agents due to their low cost and wide range of functional properties. Much of the interest in galactomannans has resulted from their unique property to provide aqueous solutions of very high viscosities (Sharman and others 1978).

\subsubsection{Guar Gum}

Guar gum is a linear non-ionic polysaccharide obtained from the ground endospore of seeds of the leguminous shrub Cyamopsis tetragonoloba. Guar gum is 
composed of a D-mannose main chain to which D-galactose units are attached at approximately every other mannose unit (Ahmed and Whistler 1950; Rafique and Smith 1950). Distribution of the galactose units along the mannose chain is disputed and is thought to be either a block (Hall and Yalpani 1980), alternate (Baker and Whistler 1975), or random pattern arranged mainly in pairs and triplets (Hoffman and Svensson 1978; McCleary and others 1985). The distribution pattern has a significant effect on the structural features of the molecule; the block polymer is predicted to be stiffer, whereas the alternating sequence is the most flexible (Petkowicz and others 1998). Changes in flexibility with the substitution may be due to the steric interaction imposed by the presence of bulky side groups, as compared to the hydroxymethyl group (Petkowicz and others 1998).

Multi-angle laser light scattering couple with size exclusion chromatography determined guar gum to have $\mathrm{M}_{\mathrm{w}}$ of $1,270 \mathrm{kDa}$ and a radius of gyration of $978 \AA$ (Frollini and others 1995). This radius of gyration value is in agreement with the predicted block substitution pattern value $(890 \AA)$ and is considerably greater than the predicted values for random $(841 \AA)$ and alternate patterns $(750 \AA)$ (Petkowicz and others 1998). The $\mathrm{M}_{\mathrm{w}}$ of guar gum has been determined by light scattering measurements to be $2,400 \mathrm{kDa}$ (Risica and others 2010) and by gel permeation chromatography to be 1,980 2,700 kDa (Cheng and others 2002; Risica and others 2005).

Guar gum behaves as a slightly stiffened random coil polymer in aqueous solution (Robinson and others 1982). Individual polymer coils are spatially separated in extremely dilute solutions but are brought into contact with one another as polymer concentration 
increases and the total hydrodynamic volume of the individual chains exceeds the volume of the solution Morris and others 1981). The individual coils start to entangle and give rise to significant coil overlap and interpenetration at the boundary between semi-dilute and concentrated regions (Risica and others 2010). Dynamic oscillatory and steady shear experiments showed that at concentrations of 1,2 , and $3 \%$ a typical entanglement network due to coil overlap was observed (Richardson and Ross-Murphy 1987). This is accompanied by a dramatic change in flow behavior and by a sudden increase in the concentration-dependence of zero-shear viscosity (Robinson and others 1982). At low polymer concentrations (0.01-0.2\%; dilute region), the specific viscosity increased approximately linearly with increasing concentration, but at higher concentrations (0.2$2 \%$; entangled domain and concentrated regime), the specific viscosity increased at a greater rate (Risica and others 2010). Higher viscosities were observed for concentrations above that at which purely by physical entanglements form due to the presence of more specific polymer-polymer interactions (hyperentanglements), in addition to non-specific physical entanglements (Morris and others 1981; Robinson and others 1982).

Guar gum is one of the most effective natural thickeners and is widely used in multiple industries due to its availability and low cost. Rheological properties of guar gum solutions of $0.1-2.0 \%$ concentration over the shear rate range $0.01-1000 \mathrm{~s}^{-1}$ at $25^{\circ} \mathrm{C}$ have been studied in detail (Sharman and others 1978; Bourbon and others 2010; Risica and others 2010). For dilute solutions at low shear rates Newtonian behavior was observed because the disruption of entanglements by the imposed deformation is replaced by new interactions between different partners, with no net change in the entanglement 
density (Risica and others 2010). The onset of shear thinning occurs when the rate of externally imposed movements becomes greater than the rate of formation of new entanglements and thus the cross-link density of the network is depleted, and the viscosity consequently reduced (Risica and others 2010). Shear thinning behavior was observed for solutions of 0.4-1.0\% concentration (Bourbon and others 2010).

\subsubsection{Cellulose Derivatives}

Cellulose is a carbohydrate composed of two repeating anhydroglucose units that occurs naturally with a high hydrophilicity on its chain structure. However, cellulose fibers contain crystalline ordered regions formed by intra- and intermolecular hydrogen bonds that render it insoluble in water. In order to solubilize cellulose, a certain fraction of hydroxyl groups are substituted by hydrophobic groups such as methyl groups or hydroxypropyl groups, which cancels some of the hydrogen bonds and breaks down the crystallinity along the anhydroglucose backbone. The properties and applications of modified celluloses are significantly influenced by the type and degree of substitution, and the molecular weight of the chain.

\subsubsection{Methyl Cellulose}

Methyl cellulose is linear, non-ionic, water-soluble derivative of cellulose, in which a fraction of the hydroxyl groups of natural cellulose are substituted with methoxyl groups. The number of substituted hydroxyl groups per anhydroglucose unit may vary from 0 to 3 with most commercial products within the range of 1.7-2. The distribution of 
methyl groups is heterogeneous along each anhydroglucose chain and from chain to chain. Mass spectroscopy measurements showed that methyl cellulose consists of highly substituted hydrophobic zones and less substituted hydrophilic zones (Arisz and others 1995). At low temperatures, water molecules form cage-like structures to surround the hydrophobic methoxyl groups, causing the methyl cellulose to become water-soluble (Haque and Morris 1993).

The scattering intensities from four methyl cellulose solutions with concentrations of $0.021-0.059 \%$ at $20^{\circ} \mathrm{C}$ were determined to be consistent with dilute solutions of flexible or semi-flexible chains in a good solvent (Kobayashi and others 1999). Steady shear viscosity and dynamic oscillatory measurements at $20-40^{\circ} \mathrm{C}$ for methyl cellulose solutions with concentrations of $2-4 \%$ showed that the solutions have similar characteristics to normal solutions of entangled hydrophilic polysaccharide coils (Haque and Morris 1993; Desbriéres and others 2000). Solutions of 2\% methyl cellulose in water at $25^{\circ} \mathrm{C}$ showed shear thinning behavior over the shear rate range 0.1-100 s $\mathrm{s}^{-1}$ (Haque and Morris 1993).

Methyl cellulose undergoes thermoreversible gelation, in which solutions form a gel upon heating and revert back to the solution state upon cooling (Savage 1957; Sarkar 1979; Nishinari and others 1997; Li and others 2002). As the temperature is increased, the viscosity of the solution decreases initially until the temperature reaches the incipient gelation temperature, at which point there is a sharp rise in viscosity, indicating gelation (Sarkar 1979). Thermogelation of methyl cellulose has been determined to occur in a two-stage process with increasing temperature above $20^{\circ} \mathrm{C}$ when the concentration 
exceeds the critical gelling concentration (Kobayashi and others 1999). The two-stage gelation mechanism is in agreement with the theoretical description of thermoreversible gelation of hydrated polymers (Tanaka and Ishida 1995; Tanaka 1996). The first stage has been attributed to hydrophobic association between zones of highly substituted units leading to the formation of a broad distribution of aggregate shapes and sizes (Desbriéres and others 1998; Kobayashi and others 1999; Desbriéres and others 2000). Upon heating, the cage structures of water molecules surrounding the methoxyl groups distort and break to expose the hydrophobic regions, leading to crosslinking and the formation of aggregates (Kato and others 1978; Sarkar and Walker 1995; Kobayashi and others 1999). The second stage corresponds to liquid-liquid phase separation accompanied by gelation (Kobayashi and others 1999). The crossover temperature between the two stages is dependent on concentration and was determined to be in the vicinity of $50{ }^{\circ} \mathrm{C}$ (Haque and Morris 1993; Kobayashi and others 1999). X-ray diffraction patterns of methyl cellulose gels revealed that the network junction points are crystalline and consist of between 4 and 8 trimethyl glucose units (Kato and others 1978).

The rate of gelation and gel strength are strongly dependent on concentration and methoxyl content and only marginally dependent on molecular weight (Sarkar 1979; Sarkar 1995; Nishinari and others 1997). Dilute solutions (0.1-0.25\%) exhibited no indication of hydrophobic association or gelation, but did show evidence of aggregation above $50{ }^{\circ} \mathrm{C}$ (Kobayashi and others 1999). Gelation is a time-dependent phenomenon and gel strength develops gradually as a solution of methyl cellulose is heated above the incipient gelation temperature (Sarkar 1979). Cosolutes that are readily soluble in water, 
such as sucrose and strong electrolytes, depress the gelation temperature as a result of gelation being dependent on the hydrophobic effect. It has been shown that gelation temperature decreases and gel strength increases as sodium chloride concentration increases (Sarkar 1979).

Methyl cellulose has broad applications in various fields including the food, pharmaceutical, cosmetic, and textile industries. The thermogelation properties of methyl cellulose have promoted its use in a variety of applications. Commercial methyl cellulose products are available in various viscosity grades that correlate to the molecular weight or chain length of the specific product. Methyl cellulose powders must be dry-blended or thoroughly dispersed in water to prevent lumping and to ensure complete hydration. Lumping results from the formation of a gelatinous layer around the powder that shields the powder from dissolving and completely hydrating (Sarkar and Walker 1995).

\subsection{Analytical Methods for Particle Size Analysis}

Particle size is an important physical particle characteristic and has been analyzed in a variety of ways. Particle size analysis is a complex matter due to the large number of dimensions required to describe a particle. A number of physical properties that correlate with characteristic geometric dimensions or equivalent dimensions have been used to determine particle size. The attributes usually used to characterize particle size include geometrical characteristics, mass, settling rate in a fluid, and field interferences such as electrical field interferences or light diffraction (Schubert 1987). 
The major goal of particle size analysis is to describe a 3-dimensional object with one number, but the sphere is the only shape that can be described by one unique number. The equivalent sphere approximation enables 3-dimensional particles to be described using one number. In the equivalent sphere approximation, a property of the particle is measured and is converted to represent that same property in a sphere. The number, now in terms of a sphere, is then used to derive one unique number to describe the particle, such as the diameter of this sphere. Particle properties that are measured must be an equivalent dimension to that of a sphere and include maximum length, minimum length, volume or surface area.

Comparison between particles can only be done if the same property on the particle was measured because different answers will be obtained from an alternative dimension. Different techniques for particle size analysis measure different properties of particles and are liable to generate different mean diameters. An electron microscope will generate the number-length mean, $\mathrm{D}[1,0]$, an image analysis method will generate the number-surface mean, $\mathrm{D}[2,0]$, an electrozone technique will generate the number-volume or number-weight mean, $\mathrm{D}[3,0]$, and laser diffraction will generate the equivalent volume mean, D[4,3] (Rawle 2008). Analytical techniques must be chosen based on the desired mean that is best suited for the particular application.

\subsubsection{Low Angle Laser Light Scattering}

Low angle laser light scattering, also known as laser diffraction, is based around the principle that particles passing through a laser beam will scatter light at an angle that 
is directly related to their size. Laser diffraction particle sizing has an applicable range of $0.1-3000 \mu \mathrm{m}$. The instrument consists of a laser, a suitable detector, and a means of passing the sample through the laser beam. He-Ne gas lasers are the most common as they offer the best stability and a good signal to noise ratio (Rawle 2008). Photosensitive silicon with a number of discrete detectors serves as the detector unit. The sample presentation system ensures that sample material passes through the laser beam as a homogeneous stream of particles in a reproducible state of dispersion. Dry powder samples are blown through the laser beam using air pressure and sucked into a vacuum cleaner. Dispersion in gases is satisfactory for particles larger than 2-5 $\mu \mathrm{m}$ (Schubert 1987).

Modern laser diffraction particle sizing instruments use the Mie Theory to calculate the size of particles from the scattering pattern generated from a field of particles as they pass through the laser beam. Mie Theory is based on Maxwell's electromagnetic field equations and is the accepted theory which accurately predicts the light scattering behavior of all materials under all conditions (Malvern 2007). Mie Theory presumes that the particles measured are perfect spheres; therefore, the equivalent sphere approximation must be used alongside Mie Theory so that the particle may be defined by one unique number. Each size of particle generates a unique scattering pattern due to the diffraction angle being inversely proportional to particle size. As the particle size decreases, the observed scattering angle increases logarithmically and scattering intensity decreases (Malvern 2007). 
Mie Theory assumes the volume of the particle based on the scattering pattern generated by the particle. The results are used to calculate the volume weighted mean, $\mathrm{D}[4,3]$, which gives the mean diameter of the particles in a given volume. Volume weighted mean accurately depicts the center point of the mass of the system and is also referred to as the mass moment mean diameter. Laser diffraction is a highly repeatable rapid measurement technique, possessing the capability to measure dry powers directly, and does not require calibration against a standard (Rawle 2008).

\subsubsection{Obscuration}

Obscuration is a measure of the amount of laser light lost due to the introduction of the sample into the analyzer beam and is dependent on the amount of sample in the beam at any one time. Light intensity measured in the central detector when a sample is present in the cell $\left(\mathrm{L}_{\mathrm{s}}\right)$ and with no sample $\left(\mathrm{L}_{\mathrm{b}}\right)$ determines obscuration. The obscuration term $(\mathrm{Ob})$ can be expressed mathematically using Equation 1:

$$
O b=1-\frac{L_{s}}{L_{b}}
$$

Obscuration is usually expressed as a percentage: $100 \mathrm{x}$ Ob. The ideal range is between 3 and 20\% depending on the sample and dispersion unit used (Malvern 2007). At low obscurations insufficient signal will be detected and result precision will be lost. At very high obscurations the calculated result may shift to smaller particle sizes due to the effects of multiple scattering (Malvern 2007). 


\section{Chapter 3: Materials and Methods}

Graham crackers (Honey Maid, Kraft Foods Global, Inc. Northfield, IL, USA) were used as targets to adhere the powder. Five $\mathrm{NaCl}$ samples of different particle sizes (Coarse, Special Flake, Flake, Fine Flake, Alberger, Cargill Incorporated. Minneapolis, MN, USA), and Fine (Microsized 66 Fine, Cargill Incorporated. Minneapolis, MN, USA) were used in the study. The other ingredients were sucrose (Mallinckrodt, Inc. St. Louis, MO, USA), canola oil (Kroger Co. Cincinnati, OH, USA), cocoa powder (The Great American Spice Co. Fort Wayne, IN, USA), ranch, BBQ, sour cream \& onion seasoning (Wild Flavors. Erlanger, KY, USA), and two types of cheese powder (Kraft Food Ingredients. Memphis, TN, USA). The hydrocolloids were gum arabic, guar gum (prehydrated FT Powder, 8/22-D Powder, TIC Gums, Inc. White Marsh, MD, USA), gellan gum, kappa-carrageen (kelcogel F, genugel carrageenan CG-130, CP Kelco. Atlanta, GA, USA), methyl cellulose with molecular weights of 14, 41, and $88 \mathrm{kDa}$, gum karaya, gum tragacanth (Sigma-Aldrich. St. Louis, MO, USA), maltodextrin, and modified starch (maltrin M040, instant pure-cote B792, Grain Processing Corporation. Muscatine, IA, USA). Graham crackers and powders were stored in a desiccator at room temperature for a minimum of 1 week prior to testing. Relative humidity within the desiccator was kept constant at $33 \%$ using a saturated magnesium chloride solution. Tests were carried out at 
$20-26^{\circ} \mathrm{C}$ and a relative humidity of $30-35 \%$. Graham crackers were cut widthwise into a final square shape 5.5 x $6.0 \mathrm{~cm}$ using a knife.

\subsection{Particle Size Determination}

Laser diffraction particle sizing was done using a Malvern Mastersizer X with a dry powder feeder (Malvern Instruments Ltd, Worcestershire, UK). The volume mean diameter $\mathrm{D}[4,3]$ of each powder was measured eight times and the average was reported as the particle size for each powder. Obscuration was maintained between 5-15\% for all samples to assure accurate measurements. Eight replicates were completed for each powder. Results are shown in Table 1.

\subsection{Powder Hydrophobicity Determination}

A separatory funnel was used to partition the components of each powder into two immiscible solvent phases. One of the phases was aqueous and the other was one of two nonpolar solvents, hexane (Mallinckrodt Baker, Inc. Phillipsburg, NJ, USA) or cyclohexane (Sigma-Aldrich. St. Louis, MO, USA). The separatory funnel was filled with $50 \mathrm{~mL}$ of each solvent and $10 \mathrm{~g}$ of powder before being shaken gently by inverting the funnel multiple times. Complete separation of the phases was allowed to occur over the course of approximately 2 hours before the phases were released from the separatory funnel. Tests done using cyclohexane were separated into 2 phases and tests done using hexane were separated into 2 phases as well as 3 phases due to the formation of a large 
interfacial region. The separated phases were heated for $30 \mathrm{~min}$ to 2 hours until complete solvent evaporation had occurred and then the remaining solute from each phase was weighed. The percentage of powder measured in each phase was used to determine powder hydrophobicity.

\subsection{Solution Preparation}

Targets were coated with water, canola oil, emulsion, sucrose, or hydrocolloid solutions.

\subsubsection{Hydrocolloid Solutions}

Gum arabic, gum karaya, guar gum, gum tragacanth, modified starch, and maltodextrin are cold water soluble and were added in powdered form to distilled water at high shear using a blender (Waring Commercial, Torrington, CT, USA). Solutions were blended for $5 \mathrm{~min}$ at 18,000 RPM and then allowed to rest for 10 min before spray application.

Gellan gum and kappa-carrageenan require heat activation for full hydration and were added to 50 and $40^{\circ} \mathrm{C}$ distilled water at high shear respectively. Solutions were blended for $5 \mathrm{~min}$, as was done with the other hydrocolloids, but were then transferred to a hot plate for further heating. Gellan gum solutions were heated to $90^{\circ} \mathrm{C}$ and kappacarrageenan solutions to $65^{\circ} \mathrm{C}$ while stirring. Solutions were allowed to cool to room temperature before spray application. 
Methyl cellulose, although soluble in cold water, must first be thoroughly dispersed in water to prevent lumping. Methyl cellulose powder was added at high shear to $1 / 3$ of the total required volume of distilled water that had been heated to $90^{\circ} \mathrm{C}$. Solutions were blended for 5 min to thoroughly wet and disperse the particles. The remainder of the water was then added at $10^{\circ} \mathrm{C}$ and the solution was placed in a freezer until the temperature of the dispersion had been held at $5^{\circ} \mathrm{C}$ for $15 \mathrm{~min}$. The dispersion was stirred every $10 \mathrm{~min}$ while in the freezer. Agitation was continued upon removal from the freezer until the dispersion reached room temperature.

Hydrocolloid solutions were prepared at a concentration of $0.5 \%$ with the exception of guar gum which was prepared at a concentration of $0.031 \%$ and modified starch and maltodextrin which were prepared at a concentration of $10 \%$. The development of high viscosity at low concentration dictated the use of guar gum a lower concentration than other hydrocolloids to enable spray application. Hydrocolloids were also prepared over a concentration range dictated by viscosity and gelation properties. A portion of the hydrocolloid solution was set aside to be used in a series of two-fold serial dilutions and the remaining portion was used in spraying the target. Dilutions were carried out by mixing equal parts distilled water and hydrocolloid solution, blending for 1 $\mathrm{min}$, and then allowing the diluted solution to rest for $10 \mathrm{~min}$. The sprayer was cleaned between solutions to ensure that the nozzle was clear and that none of the previous solution remained in the system. Solution concentrations capable of being sprayed are shown in Table 2. 


\subsubsection{Sucrose Solutions}

Sucrose solutions were prepared at an initial concentration of $50 \%$ by dissolving sucrose crystals in $50^{\circ} \mathrm{C}$ distilled water and stirring for $1 \mathrm{~h}$. A portion of the solution was set aside to be used in a series of two-fold serial dilutions and the remaining portion was used in spraying the target. Dilutions were carried out by mixing equal parts distilled water and sucrose solution and then stirring for $15 \mathrm{~min}$.

\subsubsection{Emulsions}

Emulsions were prepared using canola oil, distilled water, and lecithin (Alcolec F100 with silicon dioxide, American Lecithin Company, Oxford, CT, USA). Lecithin was added to the oil phase at a rate of $5 \%$ by weight of the oil. The oil and lecithin mixture was allowed to blend for $1 \mathrm{~min}$ at 18,000 RPM for proper dispersion. Water or hydrocolloid solution was then added to the oil and lecithin mixture at the desired proportion and was allowed to blend for 2 min at 18,000 RPM. The emulsion was sprayed immediately after blending.

\subsubsection{Combinations}

Combinations were prepared by mixing equal parts of 2 different hydrocolloid solutions that had been prepared separately. The combination was blended for $2 \mathrm{~min}$ at 18,000 RPM and then allowed to rest for 10 min before spray application. 


\subsection{Coating}

Targets were coated with $0.2 \pm 0.05 \mathrm{~g}$ of solution using an oil spray pump. Two \pm $0.2 \mathrm{~g}$ of $\mathrm{NaCl}, \mathrm{BBQ}$, ranch, $\mathrm{SC} \& \mathrm{O}$, or cheese powder or $1 \pm 0.2 \mathrm{~g}$ of cocoa powder was applied onto the sprayed target surface manually using a salt shaker. Cocoa powder has a lower density than the other powders so $1 \mathrm{~g}$ was used to equalize the volume of each powder that was applied to the target. Coated targets were then subjected to adhesion measurement evaluation. A minimum of 6 replicates were completed for each trial.

\subsection{Adhesion Measurement}

Two successive tests of increasing severity, measuring moderate and severe adhesion, were used to evaluate the adhesive capabilities of solutions with food powders. Coated targets were allowed to dry in a desiccator at room temperature with a relative humidity of $33 \%$ for $45 \mathrm{~min}$ before being subjected to adhesion measurement evaluation.

Moderate adhesion was determined by placing crackers on a vibratory feeder (Syntron, Homer City, PA, USA) that was closed off on the end using a piece of foam. The crackers were placed coated side facing up on a lateral edge at an angle inside the feeder. The feeder was allowed to vibrate on setting 8 for $15 \mathrm{~s}$ to determine moderate adhesion. A previous study had determined that after $15 \mathrm{~s}$ little additional powder came off (Buck and Barringer 2007).

Severe adhesion was determined using a portable sieve shaker (Model RX-24, W.S. Tyler Incorporated. Mentor, OH, USA). Crackers were placed coated side facing down on a standard testing sieve with opening size of $2.36 \mathrm{~mm}$ (W.S. Tyler Incorporated. 
Mentor, OH, USA). The sieve shaker was allowed to shake for $15 \mathrm{~s}$ to determine severe adhesion. Crackers were weighed before addition of solution, after addition of solution, after addition of powder, after drying in the desiccator, after vibrating, and after shaking to determine moderate (eqn 1) and severe adhesion (eqn 2).

Moderate Adhesion (\%)

$=\frac{(\text { Wt after vibrating }+ \text { Wt loss during drying })-W t \text { after solution coating }}{W t \text { after powder coating }- \text { Wt after solution coating }} \times 100$

Severe Adhesion (\%)

$=\frac{(\text { Wt after shaking }+ \text { Wt loss during drying })-\text { Wt after solution coating }}{W t \text { after powder coating }- \text { Wt after solution coating }} \times 100$

\subsection{Statistical Analysis}

Data was analyzed by using one-way analysis of variance (ANOVA) and the Tukey's family error rate with the Minitab program (Minitab 16, Minitab Inc., Pennsylvania USA). Nway ANOVA was done to test the effects of multiple factors on adhesion for each powder type with the MATLAB program (MATLAB R2013a, The MathWorks Inc., Massachusetts USA). Significance was defined as $\mathrm{p} \leq 0.05$. 


\section{Chapter 4: Results and Discussion}

\subsection{Effect of Solution and Powder Hydrophobicity on Adhesion}

Crackers were sprayed with solutions of varying water and oil content and then were coated with different food powders. Two successive tests of increasing severity, measuring moderate and severe adhesion, were used to evaluate the adhesive and cohesive capabilities of the system. Particles will stick to a surface or to each other unless the bond between them is broken by applying forces greater than the adhesive or cohesive force respectively. The particles remaining adhered on the target after each test contain bonds where the cohesion and adhesion force is greater than the force applied during that test. Subjecting the coated target to two successive tests involving application of increasingly greater force allows for insight into the adhesion properties of the system.

Five solutions of increasing oil concentration, ranging from 0 to $100 \%$ oil, were used to evaluate the effect of solution hydrophobicity on the adhesion of fine $\mathrm{NaCl}$, cheese, barbeque (BBQ), ranch, sour cream \& onion ( $\mathrm{SC} \& \mathrm{O})$, and cocoa powder. Adhesion should be determined by the affinity of the powder towards the solution based on relative hydrophilicity. A solid that has a strong affinity toward a liquid is likely to adhere well (Michalski and others 1997). Addition of sterols yields better adhesion between fruit and vegetable surfaces and coating films due to better compatibility with respect to the 
hydrophobicity of the two adhering surfaces (Nussinovitch and Hershko 1996). Capillary forces due to the presence of water have their greatest effect on a hydrophilic surface and their least effect on a hydrophobic surface (Papadakis and Bahu 1992). The 7 powders tested represent a continuum from hydrophilic to hydrophobic based on partitioning results using an aqueous and a nonpolar solvent, with fine $\mathrm{NaCl}$ being the most hydrophilic, followed by cheese powder, BBQ, ranch, SC\&O, and then cocoa powder being the least hydrophilic (Table 3 ). $\mathrm{NaCl}$ dissolved completely in the aqueous phase, while cocoa powder was the opposite, associating completely with the nonpolar phase. Cheese powder was unique in that a large percentage of material was located at the interface. BBQ powder associated mostly with the aqueous phase. Ranch and SC\&O were similar in hydrophobicity, with one powder being slightly more hydrophilic than the other depending on which nonpolar solvent was used in the test.

Adhesion of fine $\mathrm{NaCl}$ significantly decreased as oil concentration increased (Figure 4.1). Salt, being strongly hydrophilic, has a strong affinity towards water that causes greatest adhesion to be observed for a 100\% water solution. Addition of oil to water decreases the affinity of salt towards the solution and decreases adhesion. The hydrophilicity of salt, allowing it to dissolve in water, explains the high adhesion values for water. Solid bridges will be formed by recrystallization of the powder as the bridge dries if the powder has appreciable solubility in the binding fluid (Bika and others 2005). Water dissolves considerable amounts of salt as it permeates the void space between particles during the formation of liquid bridges. Subsequent evaporation of the water leads to formation of solid bridges (Adhikari and others 2001). However, formation of 
solid bridges is inhibited with oil because salt will not dissolve in oil due to the hydrophobic nature of oil. The development of solid bridges using water causes the high adhesion values for water compared to oil. Adhesion of $\mathrm{NaCl}$ has been found to increase with increasing surface oil content, but no comparisons have been made to varying oil concentration within a solution as was done in the present study (Enggalhardjo and Narsimhan 2005; Buck and Barringer 2007). These results suggest that both the amount of solution present and the makeup of the solution are important adhesion determinants.

Adhesion of BBQ, ranch, and SC\&O seasoning also significantly decreased as oil concentration increased (Figure 4.1). The BBQ seasoning has a salt content of $12 \%$, ranch has $11 \%$, and $\mathrm{SC} \& \mathrm{O}$ has $5.25 \%$. The remaining ingredients are proteins and carbohydrates so that the overall powder is hydrophilic, but not as hydrophilic as $\mathrm{NaCl}$. All three seasonings followed the same trend as fine $\mathrm{NaCl}$ but at a lower level of adhesion.

Cheese powder adhesion was greatest for emulsions of $12.5-25 \%$ oil (Figure 4.1 bottom). Two cheese powders were tested and one had greatest adhesion for an emulsion of $12.5 \%$ oil and the other for emulsions of 12.5 and $25 \%$ oil. A right skewed bell curve was observed for cheese because cheese powder contains both hydrophilic and hydrophobic portions and therefore has the greatest affinity towards a solution that is partially hydrophilic and partially hydrophobic.

Unlike the other powders, cocoa powder adhesion significantly increased as oil concentration increased (Figure 4.1). Cocoa, being hydrophobic, has a strong affinity towards oil that causes greatest adhesion to be observed for a $100 \%$ oil solution. Addition 
of oil to water has the opposite effect on cocoa as compared to salt, increasing the affinity of cocoa towards the solution and increasing adhesion.

Different solutions are required to achieve maximal adhesion depending on the type of powder (Figure 4.1). Solutions of similar hydrophobicity to the powder gave the greatest adhesion. Therefore, powder hydrophobicity should be considered when selecting solutions for adhesive purposes. 

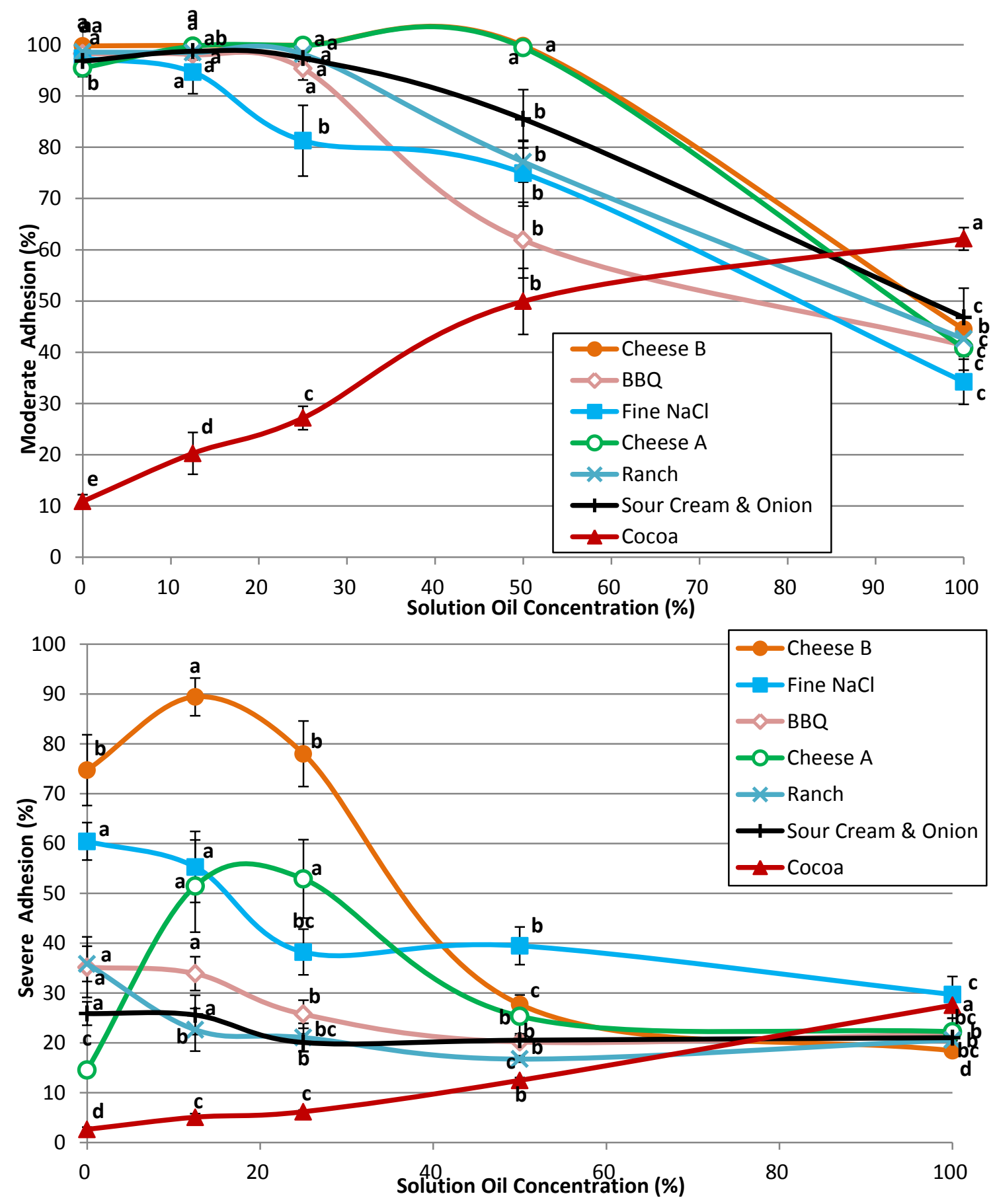

Figure 4.1 Effect of solution hydrophobicity on fine $\mathrm{NaCl}, \mathrm{BBQ}, \mathrm{SC} \& \mathrm{O}$, cheese A,

cheese B, and cocoa powder adhesion measured by moderate (top) and severe (bottom) methods. Means that share a letter within a powder group are not significantly different. 
Unlike the other powders, coating evenness and visual appeal of BBQ seasoning increased as oil concentration increased despite the significant decrease in BBQ seasoning adhesion (Figure 4.2). BBQ seasoning color was altered as contact was made with the coating solution and as time elapsed during the drying period. As oil concentration increased the color of BBQ seasoning changed from a dark red/brown to a lighter orange color. Cocoa powder color was also dependant on solution oil concentration (Figure 4.2). The color of crackers coated in cocoa powder became darker as oil concentration increased.

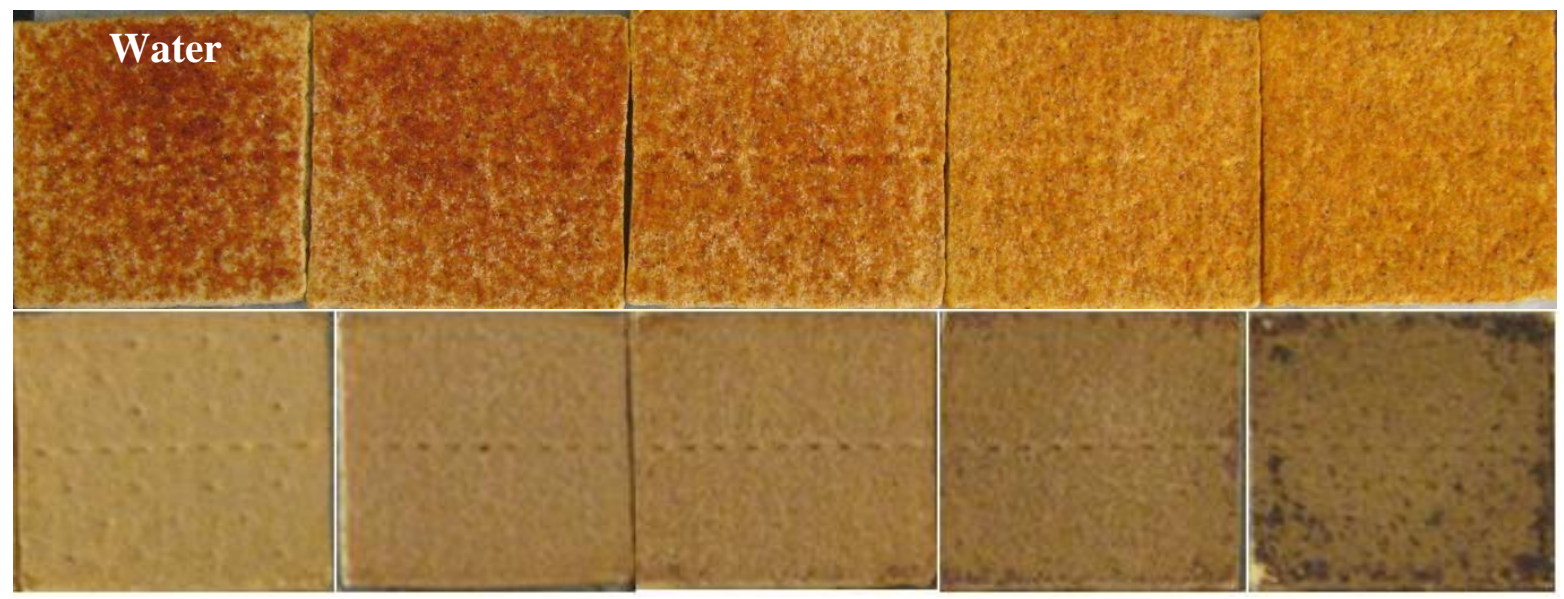

Figure 4.2 Images of crackers coated with BBQ seasoning (top) and cocoa powder (bottom) using five solutions ranging from 0-100\% oil. 


\subsection{Effect of Hydrocolloid Type on Adhesion}

Seven hydrocolloid solutions were prepared to evaluate the ability of different hydrocolloid types to increase the adhesion of different food powders. Only severe adhesion values are reported because significant differences between hydrocolloids were not usually observed for moderate adhesion values. Adhesion of $\mathrm{NaCl}, \mathrm{SC} \& \mathrm{O}$, ranch, $\mathrm{BBQ}$, and cheese powder to the target surface was significantly greater using most hydrocolloid solutions than using water alone, while no improvement with the addition of hydrocolloids was seen for cocoa powder (Figures 4.3-4.4).

Hydrocolloid type affected adhesion improvement for $\mathrm{NaCl}, \mathrm{SC} \& \mathrm{O}$, ranch, and BBQ seasoning (Figure 4.3). For fine $\mathrm{NaCl}$, gellan gum and kappa-carrageen gave the greatest adhesion at $90 \%$ and $89 \%$ respectively; followed by methyl cellulose at $84 \%$, gum karaya at $79 \%$, gum tragacanth at $77 \%$, gum arabic at $70 \%$, and guar gum at $66 \%$ adhesion. Coarse $\mathrm{NaCl}, \mathrm{SC} \& \mathrm{O}$, ranch, and BBQ seasoning generally followed the same trend as fine $\mathrm{NaCl}$, but with lower overall adhesion.

Hydrocolloid structural differences, including the presence or absence of branching, substitution of sugar units, and molecular weight were significant contributing factors to adhesion of the powders to the target surface, while ionic charge was not a significant factor contributing to adhesion. Adhesion was greatest for non-substituted linear molecules (gellan gum, kappa-carrageen, and methylcellulose), followed by branched molecules (gum karaya, gum tragacanth, and gum arabic), and then substituted 
linear molecules (guar gum) (Figure 4.3). Linear polymer chains can associate intimately with each other through intermolecular hydrogen bonding to form a network. Conversely, branched gums assume a globular conformation that prevents polymer chains from associating intimately with each other. The presence of substituent groups on linear polymer chains creates steric hindrance that prevents the polymer chains from associating intimately. Structural features enabling molecules to undergo gelation, such as linear polymer arrangement, appear to relate to adhesive capabilities. Hydrocolloids capable of gelation (gellan gum, kappa-carrageenan, methyl cellulose, and gum karaya) gave better adhesion than non-gelling hydrocolloids (gum tragacanth, gum arabic, and guar gum). Increasing molecular weight generally increased adhesion within a structural grouping (Figure 4.3). In the non-substituted linear group, gellan gum and kappacarrageenan with molecular weights of 434-490 kDa and 468-675 kDa respectively, gave greater adhesion than methylcellulose at $41 \mathrm{kDa}$ (Dentini and others 1988; Milas and others 1990; Viebke and others 1995; Viebke and Williams 2000). In the branched group, adhesion was greatest for gum karaya at $9,500 \mathrm{kDa}$, followed by gum tragacanth at 840 kDa, and gum arabic at 460-720 kDa (Krubal and Gralén 1948; Gralén and Karrholm 1950; Duvallet and others 1989; Randall and others 1989).

The effect of molecular weight on adhesion was further investigated by evaluating the adhesive capabilities of three forms of methylcellulose with molecular weights ranging from 14 to $88 \mathrm{kDa}$. The three forms of methyl cellulose were tested at concentrations of $0.25 \%$ and $0.5 \%$ using fine $\mathrm{NaCl}$. Adhesion using methylcellulose with molecular weights of 14,41 , and $88 \mathrm{kDa}$ was 71,73 , and $79 \%$ at a concentration of 
$0.25 \%$, and was 75,84 , and $84 \%$ at a concentration of $0.5 \%$. The results indicate that increasing molecular weight significantly increases adhesion and supports the conclusion that molecular weight is a factor affecting adhesion within hydrocolloid structural groupings. 


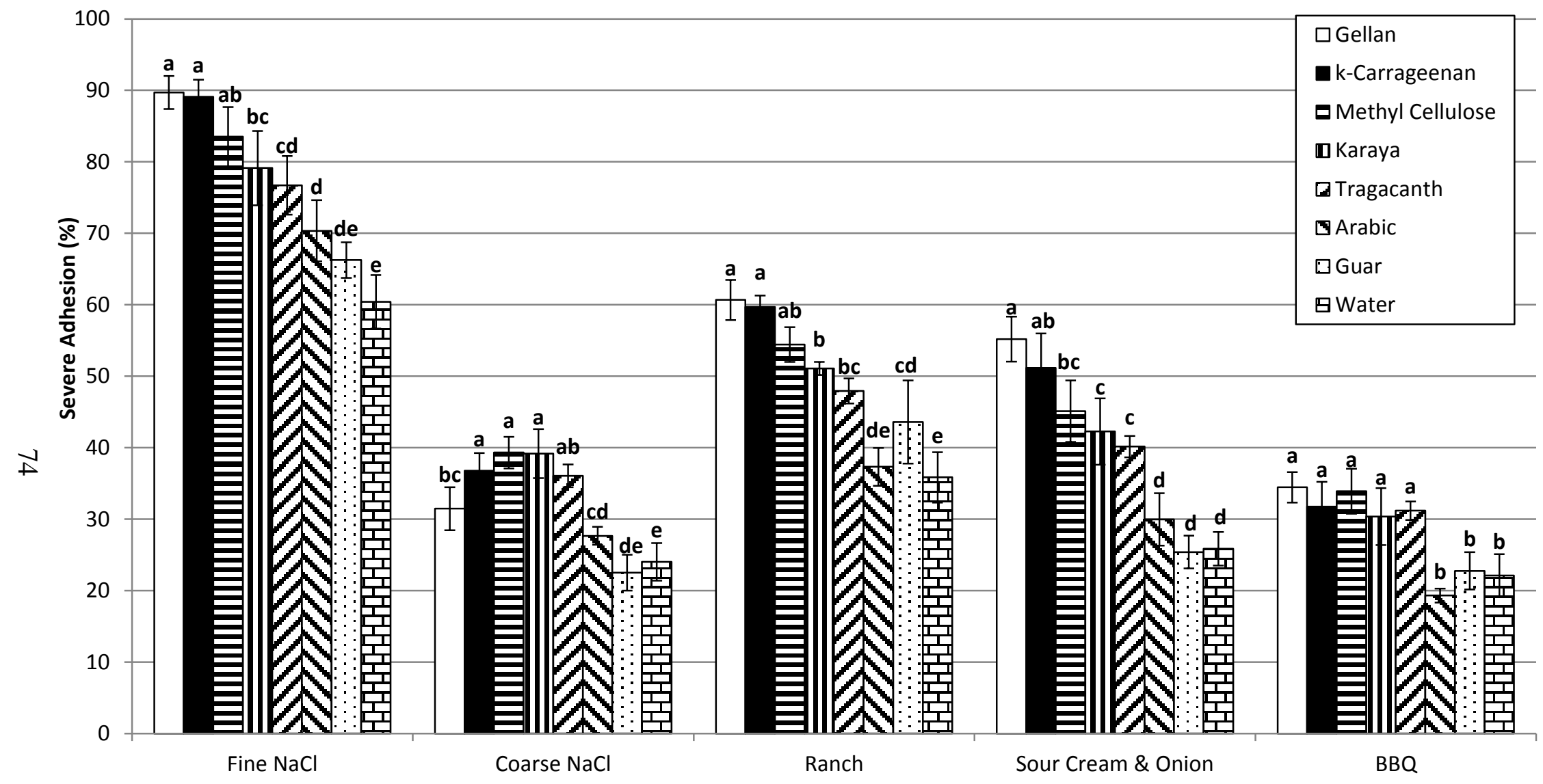

Figure 4.3 Effect of hydrocolloid type on fine and coarse $\mathrm{NaCl}, \mathrm{SC} \& \mathrm{O}$, ranch, and $\mathrm{BBQ}$ seasoning adhesion. Means that share a letter within a powder group are not significantly different. 
Two cheese powders were tested using water and $12.5 \%$ emulsion solutions with and without the addition of hydrocolloids (Figure 4.4). Similar to the more hydrophilic powders, adhesion of cheese powder using most hydrocolloid solutions was significantly greater than using water alone; thus, hydrocolloids can be used to increase adhesion. In addition, adhesion using most hydrocolloid solutions in water was not significantly different than in an emulsion and was greater than the emulsion alone; thus, hydrocolloids can be used to replace oil in the solution while maintaining the same level of adhesion.

Gum arabic was the best hydrocolloid for both cheese powders and increased adhesion to a similar value as the best hydrocolloids with fine $\mathrm{NaCl}$ (Figure 4.3- 4.4). It is possible that the arabinogalactan-protein complex, which is largely responsible for the emulsification properties of gum arabic, is also responsible for the superior cheese powder adhesion results obtained with gum arabic in water and in an emulsion. The arabinogalactan-protein complex contains polypeptides along the periphery that enable the molecule to adsorb onto hydrophobic surfaces and explain its ability to sterically stabilize emulsions and dispersions (Randall and others 1989). By lowering the interfacial tension between oil and water, gum arabic functions beyond the traditional hydrocolloid role of emulsion stabilization through modification of the rheological properties of the aqueous phase. The capacity of gum arabic to interact with hydrophilic and hydrophobic components appears to be important with cheese powder, which also contains both hydrophilic and hydrophobic portions as do emulsions. The presence or absence of branching, substitution of sugar units, and molecular weight were not significant 
contributing factors to adhesion of cheese powder as was the case with adhesion of salt, SC\&O, ranch, and BBQ seasoning. The results indicate that hydrocolloids could replace oil within the solution while improving or maintaining the same level of cheese powder adhesion, which would provide a lower fat content without negatively affecting seasoning adhesion.

Cocoa powder, the most hydrophobic powder evaluated, was tested using water and $50 \%$ emulsion solutions with and without the addition of hydrocolloids to determine if hydrocolloids could replace oil within the solution while improving or maintaining the same level of cocoa powder adhesion. Adhesion of cocoa powder using hydrocolloid solutions was not significantly different than using water alone (Figure 4.4). Addition of hydrocolloids to an emulsion also gave adhesion values that were not statistically different from an emulsion without hydrocolloids. Hydrocolloid solutions are hydrophilic and are therefore ineffective adhesives for cocoa powder. The associations that occur between hydrocolloid molecules and water molecules during the solvation process lead to a strongly hydrophilic molecule that does not relate well to the hydrophobicity of cocoa powder. Liquids interact with solid particles composed of molecules of similar polarity (Dopfer and others 2012). Despite possessing significant hydrophobic portions that could possibly interact with cocoa, gum tragacanth and gum arabic did not show significantly greater adhesion values than gums lacking significant hydrophobic portions. The possible interactions between hydrophobic components of the gums and cocoa were likely inhibited by the water molecules associated with the hydrophilic regions of the gums and the water continuous phase. The hydrophobic nature of cocoa powder prohibits it from 
associating intimately and dissolving into the hydrophilic hydrocolloid solutions which limits adhesion. 


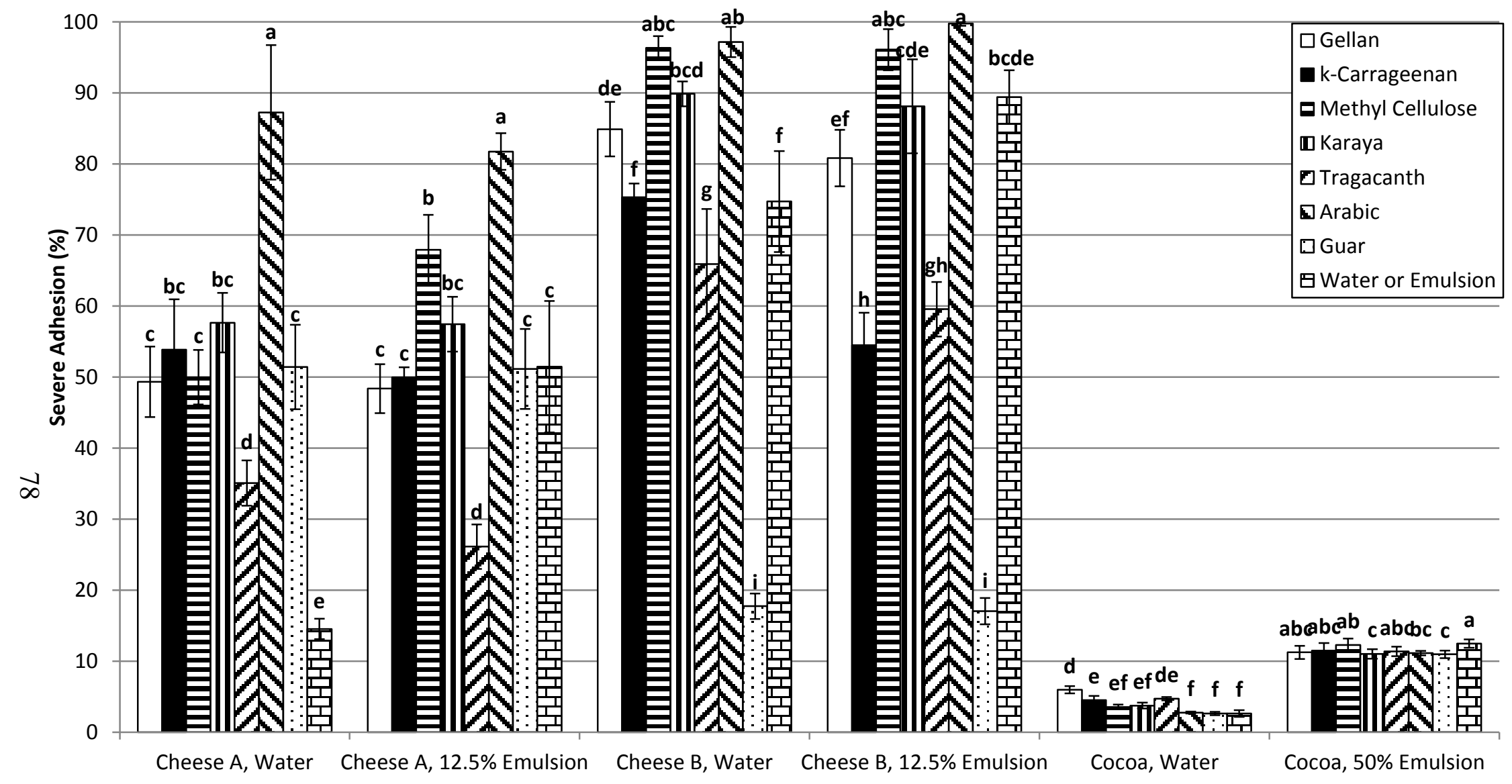

Figure 4.4 Effect of hydrocolloid type on cheese powder A and B and cocoa powder adhesion. Means that share a letter within a powder group are not significantly different. 
Combinations of hydrocolloids were tested using hydrocolloids that provided the highest adhesion values for the food powders. SC\&O and BBQ powders were chosen to use with the hydrocolloid combinations because these two powders had the lowest levels of adhesion when using individual hydrocolloid solutions; therefore, they also had the greatest room for improvement. Hydrocolloid combinations did not significantly improve adhesion over the higher of the individual hydrocolloids (Figure 4.5). Hydrocolloids are known to exhibit synergistic interactions and to generate unique rheological properties upon mixing (Dea and others 1977; Fernandes and others 1991; Goycoolea and others 1995). The associated characteristics and rheological properties of hydrocolloid blends has proven beneficial to properties such as thickening and gelation, enabling mixed gels to form at total polymer levels far below those required for gelation of either polysaccharide alone (Le Cerf and Muller 1994). The present investigation determined that adhesive properties were not significantly improved using hydrocolloid combinations as might be expected based on the synergistic interactions of other mixed systems. 


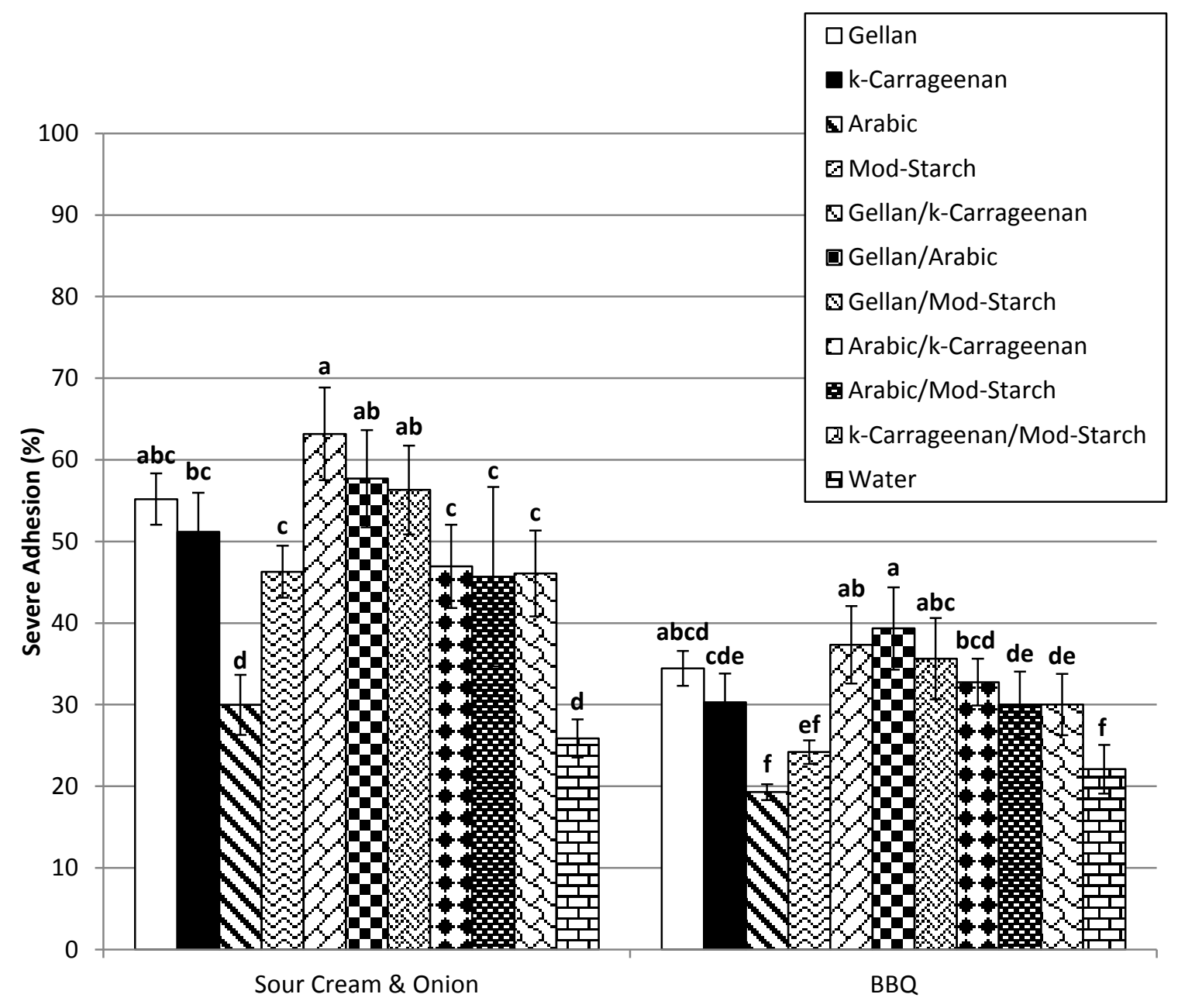

Figure 4.5 Effect of hydrocolloid combinations on SC\&O and BBQ seasoning adhesion.

Means that share a letter within a powder group are not significantly different.

Adhesion of $\mathrm{NaCl}$, cheese powder, $\mathrm{BBQ}$, ranch, and $\mathrm{SC} \& \mathrm{O}$ to the target surface was significantly greater using most hydrocolloid solutions than using water alone, while no improvement with the addition of hydrocolloids was seen for cocoa powder (Figures 4.3-4.4). The results indicate that hydrocolloids could replace oil within the solution 
while improving or maintaining the same level of adhesion for seasonings, which would lower calories and be of interest to the food industry.

\subsection{Effect of Hydrocolloid Concentration on Salt Adhesion}

The hydrocolloids were tested over a range of concentrations to evaluate the effect of concentration on adhesion. A hydrocolloid solution concentration of $0.5 \%$ provided the greatest adhesion for most hydrocolloids with the exceptions of methyl cellulose being better at higher concentrations and guar gum being better at lower concentrations (Figure 4.6). Adhesion for gellan gum, kappa-carrageen, gum karaya, and gum arabic did not change significantly over the concentration range tested. Adhesion for methyl cellulose and tragacanth increased significantly as concentration increased. Adhesion for guar gum significantly decreased as concentration increased from $0.031 \%$ to $0.063 \%$. Viscosity and gelation properties impose limitations on the concentration range capable of being sprayed. Testing was not continued beyond a concentration of $1 \%$ for gellan gum and kappa-carrageen because both gums underwent gelation at this concentration. Development of high viscosity prohibited methyl cellulose and gum karaya from being sprayed at concentrations greater than $2.5 \%$, and gum tragacanth and guar gum from being sprayed at concentrations greater than 0.5 , and $0.063 \%$ respectively. 


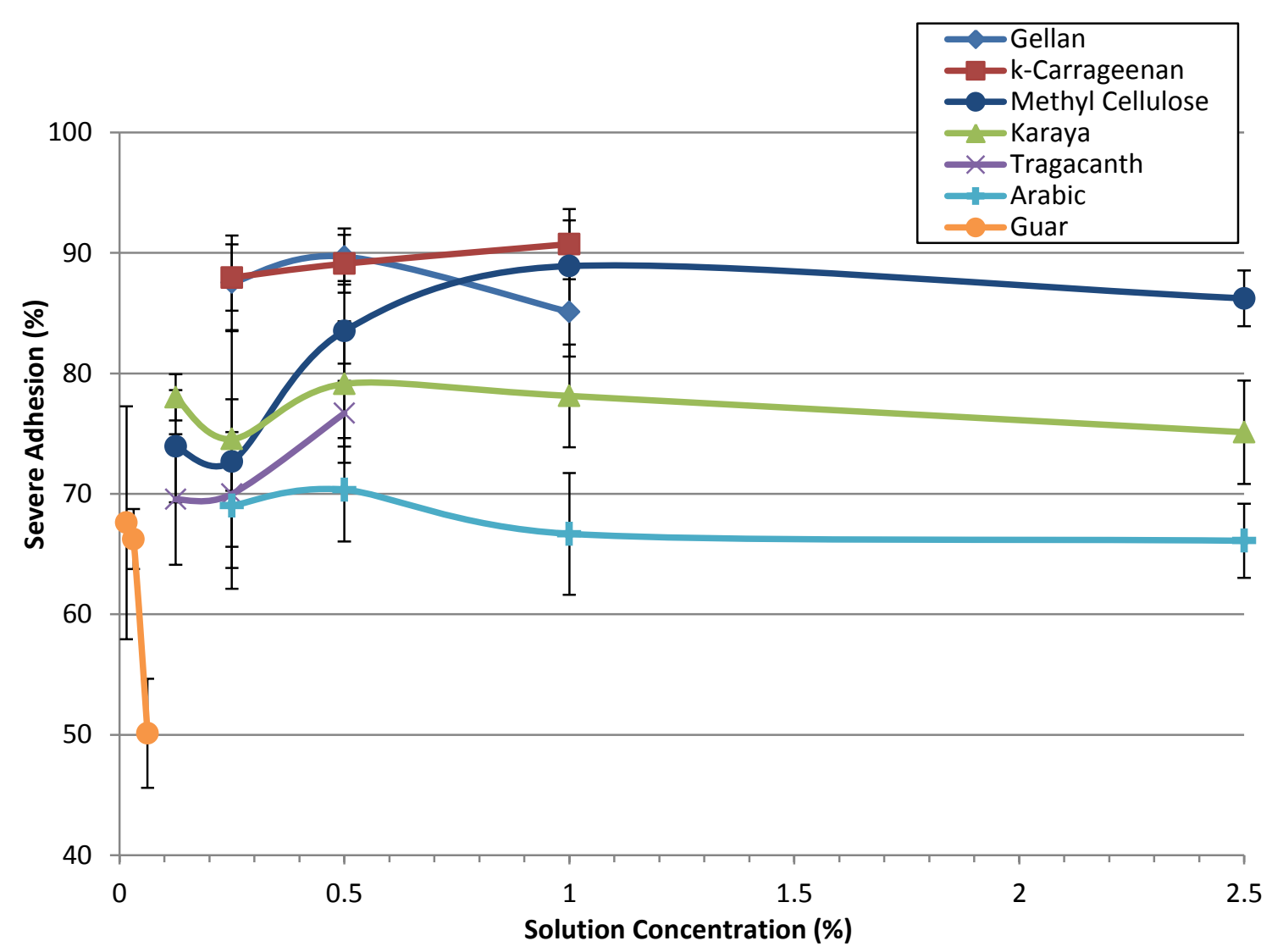

Figure 4.6 Effect of hydrocolloid concentration on fine $\mathrm{NaCl}$ adhesion.

\subsection{Effect of Solution Sucrose Concentration on Adhesion}

Solutions of increasing sucrose concentration were used to evaluate the effect of sucrose concentration on adhesion of different food powders. As sucrose concentration increased, adhesion of the smaller powders, fine $\mathrm{NaCl}$ (58 um), cheese $\mathrm{B}$ (119 um), BBQ (290 um), ranch (185 um), and SC\&O (161 um) significantly decreased, adhesion of 
large sized NaCls (254 to 484 um) significantly increased, and adhesion of cocoa powder did not significantly change (Figure 4.7).

Adhesion of fine $\mathrm{NaCl}$ (58 um), cheese B (119 um), BBQ (290 um), ranch (185 um), and SC\&O (161 um) decreased significantly as solution sucrose concentration increased due to the small particle size of the powders (Figure 4.7). The small interparticle spaces characteristic of these powders make them highly dependent on water mobility for adhesion. Addition of sucrose to water affects the ability of water to absorb onto a particle surface due to a decrease in water activity. As water mobility decreases, the availability of water molecules to absorb onto a particle surface decreases and extent of liquid bridge formation is limited. Decreased water activity corresponds to exponential decreases in capillary condensation size and significant decreases in liquid bridge strength (Billings and others 2006). Liquid bridges are fundamental to particle adhesion and their strength is dependent on the portion of the total void space between particles occupied by liquid. Attractive capillary forces develop as a consequence of the formation of liquid bridges between contacting bodies and result in a combined pull of solid particles by negative pressure and interfacial tension exerted by the liquid along the wetted perimeter (Massimilla and Donsi 1976; Adhikari and others 2001). Adhesion of fine $\mathrm{NaCl}, \mathrm{BBQ}$, ranch, $\mathrm{SC} \& \mathrm{O}$, and cheese $\mathrm{B}$ decreases with increasing sucrose concentration due to a decrease in adsorption of water molecules taking place on the particle surface and the subsequent decrease in liquid bridge formation.

Adhesion of large sized NaCls (254 to 484 um) increases with increasing sucrose concentration due to the interparticle spaces being filled more completely with crystalline 
material than what would be seen with the $100 \%$ water solution (Figure 4.7). The strength of the interparticle bond depends on the amount of solid deposited and the crystal structure (Papadakis and Bahu 1992). Increasing sucrose concentration results in the interparticle spaces of large particles being more completely filled with crystalline material and results in stronger solid bridges as the solution dries. The positive effect on adhesion of having the interparticle spaces filled more completely with crystalline material is greater than the negative effect of decreased water mobility for larger particles; thus, adhesion increases as sucrose concentration increases.

Adhesion of cocoa powder did not significantly change as solution sucrose concentration increased (Figure 4.7). Sucrose solutions are hydrophilic and are therefore ineffective adhesives for cocoa powder.

Significant changes in $\mathrm{NaCl}$ adhesion occurred as sucrose concentration increased above $25 \%$, while no significant change occurred from $0-25 \%$. Adhesion of $400 \mathrm{um} \mathrm{NaCl}$ significantly increased as concentration of sucrose or glucose in the solution increased (Ren and Barringer 2009). Similarly, adhesion between sesame seeds increased as surface sucrose content increased (Takenaka and others 2006). The effectiveness of sugar solutions as an adhesive was dependent on particle size of the powder and relative hydrophobicity. Increasing sucrose concentration decreased adhesion of smaller particles, but increased adhesion of larger particles. 


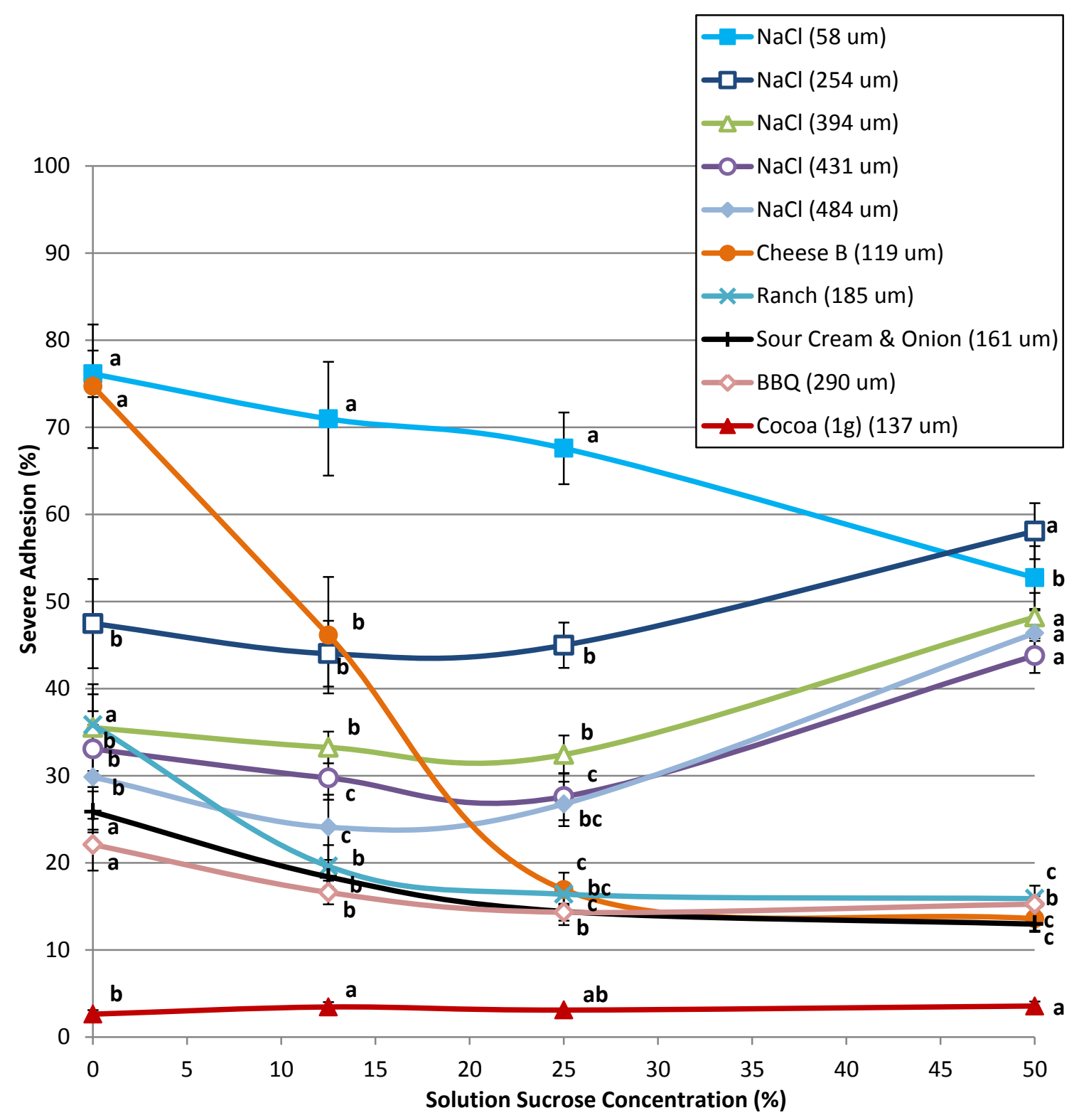

Figure 4.7 Effect of sucrose concentration on 58, 354, 394, 431, and 484 um NaCl, BBQ, ranch, SC\&O, cheese B, and cocoa powder adhesion. Means that share a letter within a powder group are not significantly different. 


\subsection{Effect of Salt Size on Adhesion}

Five different sizes of salt ranging from 58-484 $\mu \mathrm{m}$ were used to evaluate the effect of particle size on adhesion using water, 50\% sucrose solution, and oil. Adhesion of salt significantly increased with decreasing salt size (Figure 4.8). There was no further increase in adhesion with oil and 50\% sucrose solutions as particle size decreased below $254 \mu \mathrm{m}$.

Increased adhesion with smaller particles arises due to the strengthening of intermolecular forces and material bridges. The effect of particle size on adhesion is based in the fact that the ratio of particle adhesion to particle weight is inversely proportional to the square of the particle size (Schubert 1987). This inverse relationship results in an increase in surface area per unit volume. As a result of the increase in surface area per unit volume, surface forces become dominant over gravitational forces in small particulates (Adhikari and others 2001). The smaller the particle diameter, the larger the van der Waals force and capillary force with respect to particle weight force (Massimilla and Donsi 1976).

Material bridges are affected in a number of ways by particle size. The higher surface area to mass ratio characteristic of smaller particles allows for greater amounts of powder to dissolve in the liquid located in the interparticle spaces. Strength of interparticle bridges depends on the amount of solid deposited and the crystal structure; therefore, stronger bridges are formed between smaller particles and adhesion is greater 
(Papadakis and Bahu 1992). However, the base powder must have appreciable solubility in the granulating fluid, such as salt in water, for this effect to occur.

The influence of particle size on particle contact area and the void space dimensions between particles has dramatic effect on intermolecular forces and material bridges. The strength of material bridges and van der Waals force are increased by the decreasing interparticle distance that accompanies decreasing particle size. Smaller bridges resulting from smaller distances between particles develop higher strength as the solvent evaporates (Tardos and Gupta 1996). The strength of liquid bridges also increases with smaller interparticle distances. This is due to increases in capillary pressure and resulting capillary forces that are primarily responsible for the strength of liquid bridges. Strength of van der Waals force is dependent on contact area and the distance between two surfaces and is at a maximum when particles are in intimate contact with each other. Adhesion of sugar onto saltine crackers decreased with increasing particle size from 23$443 \mu \mathrm{m}$ because increasing particle size decreases the particle contact area which decreases the attraction force (Halim and Barringer 2006). Increasing particle size decreases the strength of van der Waals force through an increase in interparticle distance and a decrease in particle contact area.

Previous studies have also shown increased adhesion with decreasing particle size. Adhesion of salt to food targets including carrot, bread, lettuce and cracker significantly increased with decreasing salt size from 332-119 $\mu \mathrm{m}$ (Sumonsiri and Barringer 2011). Adhesion of salt to potato chip surface significantly increased with decreasing salt size from 388-25 $\mu \mathrm{m}$ (Buck and Barringer 2007). Adhesion rates of 
particles to food surfaces are significantly affected by the strengthening of intermolecular forces and material bridges demonstrated with decreasing particle size.

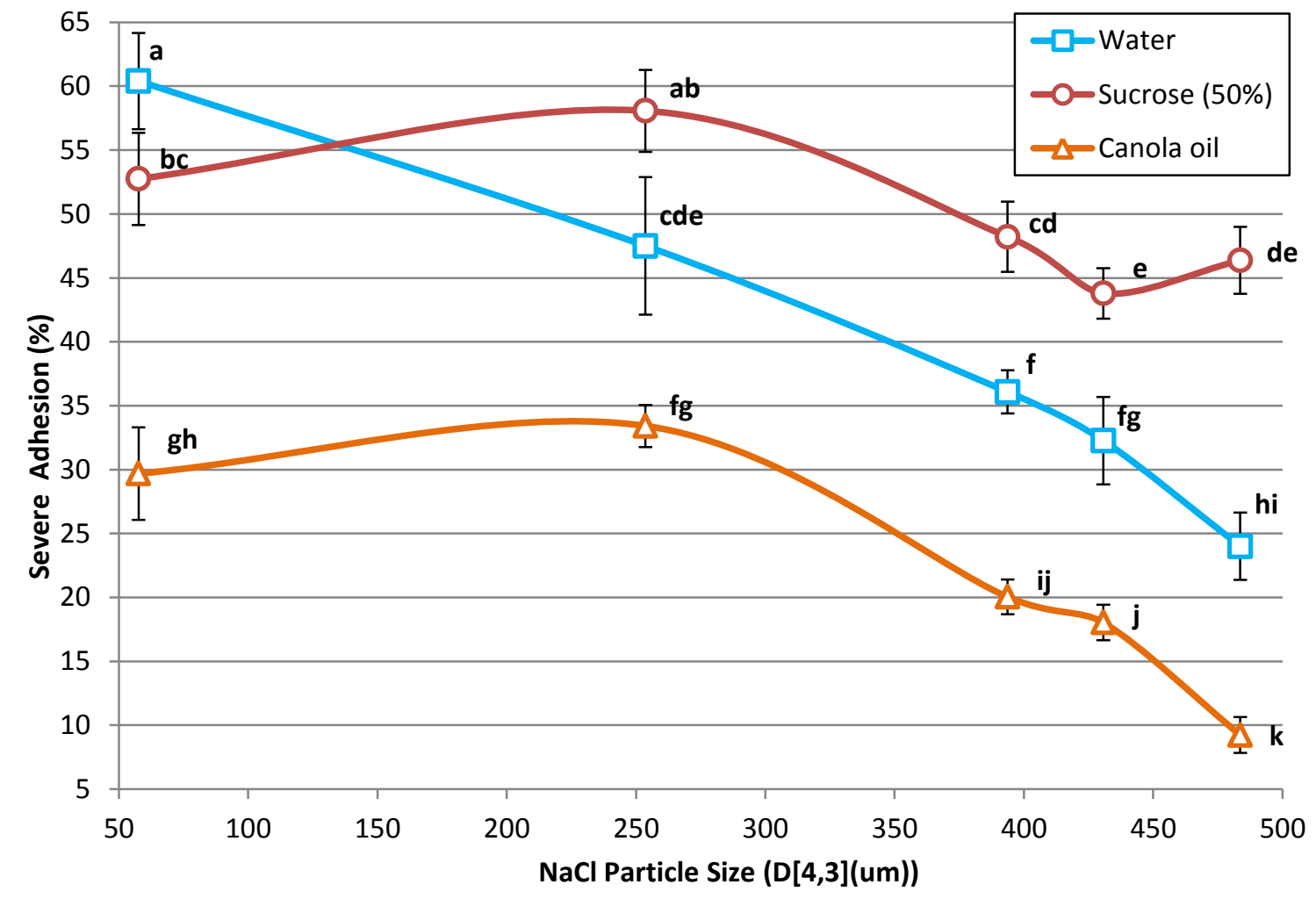

Figure 4.8 Effect of $\mathrm{NaCl}$ size on adhesion using water, $50 \%$ sucrose solution, and oil. Means that share a letter are not significantly different.

$\mathrm{N}$-way analysis of variance (ANOVA) was done to test the effects of particle size, oil content, sucrose content, and hydrocolloid type on adhesion for each powder type. The effect of particle size was only evaluated for salt and was determined to be the most important factor for salt. For cheese, BBQ, ranch, and SC\&O the factors were determined 
to have similar importance. Oil concentration was determined to be the most important factor for cocoa. 


\section{Chapter 5: Conclusions}

$\mathrm{NaCl}, \mathrm{BBQ}$, ranch, and $\mathrm{SC} \& \mathrm{O}$ showed greatest adhesion with water, cheese powder with an emulsion, and cocoa powder with oil, due to hydrophilicity. Solutions of similar hydrophobicity to the powder gave the greatest adhesion. Therefore, powder hydrophobicity should be considered when selecting solutions for adhesive purposes. Hydrocolloids improve the adhesion of $\mathrm{NaCl}$, sour cream \& onion, ranch, and $\mathrm{BBQ}$ seasoning over using water alone. Hydrocolloid structural differences, including the presence or absence of branching, substitution of sugar units, and molecular weight were significant contributing factors to adhesion of the powders to the target surface. Adhesion was greatest for non-substituted linear molecules (gellan gum, kappa-carrageen, and methylcellulose), followed by branched molecules (gum karaya, gum tragacanth, and gum arabic), and then substituted linear molecules (guar gum). Increasing molecular weight generally increased adhesion within a structural grouping. Hydrocolloids can replace oil within the solution while improving or maintaining the same level of adhesion for cheese powder. Hydrocolloids are ineffective with cocoa powder due to differences in hydrophilicity that result in insolubility and low adhesion values. Hydrocolloid combinations did not significantly improve adhesion over the higher of the individual hydrocolloids. Effect of hydrocolloid concentration was dependent on hydrocolloid type, with $0.5 \%$ being the optimum concentration for most gums. Adhesion using sucrose 
solutions was determined by particle size and relative hydrophobicity. Adhesion of $\mathrm{NaCl}$ significantly increased with decreasing $\mathrm{NaCl}$ size using oil, water, and sucrose solutions. Additional research should be done involving the sensory impacts of using hydrocolloid solutions on flavor release and mouthfeel. 


\section{References}

Adhikari B, Howes T, Bhandari BR, Truong V. 2001. Stickiness in foods: A review of mechanisms and test methods. Int J Food Properties 4(1):1-33.

Adhikari B, Howes T, Shrestha A, Bhandari BR. 2007. Effect of surface tension and viscosity on the surface stickiness of carbohydrate and protein solutions. J Food Eng 79(2007):1136-1143.

Ahmed ZF, Whistler RL. 1950. The structure of guaran. Journal of the American Chemical Society 72(6):2524-2525.

Amara AA, Drean JY, Nardin M, Frydrych R. 2007. Peel test: a tool to assess the stickiness of honeydew sugar. Research J Textiles and Apparel 11(2):49-59.

Anderson DMW. 1978. Chemotaxonomic aspects of the chemistry of Acaci gum exudates. Kew Bulletin 32(3):529-536.

Anderson DMW, Bridgeman MME. 1985. The composition of the proteinaceous polysaccharides exuded by Astragalus microcephalus, A. gummifer and A. kurdicus - the sources of Turkish gum tragacanth. Phytochemistry 24(10):23012304.

Anderson DMW, Bridgeman MME. 1988. The chemical characterization of the test article used in toxicological studies of gum tragacanth. Food Hydrocolloids 2(1):51-57.

Anderson DMW, Grant DAD. 1989. Chemical compositions of the nitrogen containing gum tragacanth exudates from Asiatic Astragalus species, grown in North America. Food Hydrocolloids 3(3):217-223.

Anderson DMW. Hendrie A, Munro AC. 1972. The amino acid and amino sugar composition of some plant gums. Phytochemistry 11(2):733-736.

Anderson DMW, Hirst E, Rahman S. 1966a. Studies on uronic acid materials. Part XVIII. Light-scattering studies on some molecular-weight fractions from Acacia senegal gum. Carbohydrate Research 3(1967):308-317. 
Anderson DMW, Hirst E, Stoddart JF. 1966b. Studies on uronic acid materials. Part XVII. Some structural features of Acacia senegal gum (gum arabic). Journal of the Chemical Society C: Organic 0(1966):1959-1966.

Anderson DMW, Howlett JF, McNab CGA. 1985a. The amino acid composition of the proteinaceous component of gum tragacanth (Asiatic Astragalus spp.). Food Additives and Contaminants: Chemistry, Analysis, Control, Exposure and Risk Assessment 2(4):231-235.

Anderson DMW, Howlett JF, McNab CGA. 1985b. The amino acid composition of the proteinaceous component of gum arabic (Acacia Senegal (L.) Willd.). Food Additives and Contaminants: Chemistry, Analysis, Control, Exposure and Risk Assessment 2(3):159-164.

Anderson DMW, Howlett JF, McNab CGA. 1985c. The amino acid composition of the proteinaceous component of gum karaya (Sterculia spp.). Food Additives and Contaminants: Chemistry, Analysis, Control, Exposure and Risk Assessment 2(3):153-157.

Anderson DMW, Howlett JF, McNab CGA. 1985d. The amino acid composition of the proteinaceous component of guar gum (Cyamopsis tetragonolobus). Food Additives and Contaminants: Chemistry, Analysis, Control, Exposure and Risk Assessment 2(4):225-230.

Anderson DMW, Stoddart JF. 1966. Studies on uronic acid materials. Part XV. The use of molecular-sieve chromatography in studies on Acacia senegal gum (gum arabic). Carbohydrate Research 2(1966):104-114.

Anderson NS, Campbell JW, Harding MM, Rees DA, Samuel JWB. 1969. X-ray diffraction studies of polysaccharide sulphates: Double helix models for kappaand iota-carrageenans. Journal of Molecular Biology 45(1):85-88, IN5, 89-97.

Arisz PW, Kauw HJJ, Boon JJ. 1995. Substituent distribution along the cellulose backbone in O-methylcelluloses using GC and FAB-MS for monomer and oligomer analysis. Carbohydrate Research 271(1):1-14

Aspinall GO. 1967. The exudate gums and their structural relationship to other groups of plant polysaccharides. Pure and Applied Chemistry 14(1):43-56.

Aspinall GO, Baillie J. 1963a. Gum tragacanth. Part I. Fractionation of the gum and the structure of tragacanthic acid. Journal of the Chemical Society 1963(0):17021714. 
Aspinall GO, Baillie J. 1963b. Gum tragacanth. Part II. The arabinogalactan. Journal of the Chemical Society 1963(0):1714-1721.

Aspinall GO, Charlson AJ, Hirst EL, Young R. 1963. The location of L-rhamnopyranose residues in gum arabic. Journal of the Chemical Society 1963(0):1696-1702.

Aspinall GO, Fraser RN. 1965. Plant gums of the genus Sterculia. Part II. Sterculia caudata gum. Journal of the Chemical Society 1965(0):4318-4325.

Aspinall GO, Fraser RN, Sanderson GR. 1965. Plant gums of the genus Sterculia. Part III. Sterculia setigera and Cochlospermum gossypium gums. Journal of the Chemical Society 1965(0):4325-4329.

Aspinall GO, Nasir-ud-din. 1965. Plant gums of the genus Sterculia. Part I. The main structural features of Sterculia urens gum. Journal of the Chemical Society 1965(0):2710-2720.

Aspinall GO, Sanderson GR. 1970a. Plant gums of the genus Sterculia. Part IV. Acidic oligosaccharides from Sterculia urens gum. Journal of the Chemical Society 1970(16):2256-2258.

Aspinall GO, Sanderson GR. 1970b. Plant gums of the genus Sterculia. Part V. Degradation of carboxy-reduced Sterculia urens gum. Journal of the Chemical Society 1970(16):2259-2264.

Baker CW, Whistler RL. 1975. Distribution of D-galactosyl groups in guaran and locustbean gum. Carbohydrate Research 45(1):237-243.

Balaghi S, Mohammadifar MA, Zargaran A. 2010. Physicochemical and rheological characterization of gum tragacanth exudates from six species of Iranian Astragalus. Food Biophysics 5(2010):59-71.

Ben-Zion O, Nussinovitch A. 1997. Physical properties of hydrocolloid wet glues. Food Hydrocolloids 11(4):429-442.

Bika D, Tardos GI, Panmai S, Farber L, Michaels J. 2005. Strength and morphology of solid bridges in dry granules of pharmaceutical powders. Powder Technology 150(2005):104-116.

Billings SW, Bronlund JE, Paterson AHJ. 2006. Effects of capillary condensation on the caking of bulk sucrose. J Food Eng 77(4):887-895. 
Borgström J, Piculell L, Viebke C, Talmon Y. 1996. On the structure of aggregated kappa-carrageenan helices. A study by cryo-TEM, optical rotation and viscometry. International Journal of Biological Macromolecules 18(3):223-229.

Bourbon AI, Pinheiro AC, Ribeiro C, Miranda C, Maia JM, Teixeira JA, Vicente AA. 2010. Characterization of galactomannans extracted from seeds of Gleditsia triacanthos and Sophora japonica through shear and extensional rheology: Comparison with guar gum and locust bean gum. Food Hydrocolloids 24(23):184-192.

Bradley R.S. 1932. The cohesive force between solid surfaces and the surface energy of solids. Philosophical Magazine Series 7 13(86):853-862.

Brito ACF, Silva DA, de Paula RCM, Feitosa JPA. 2004. Sterculia striata exudate polysaccharide: characterization, rheological properties and comparison with Sterculia urens (karaya) polysaccharide. Polymer International 53(2004):10251032.

Brito ACF, Sierakowski MR, Reicher F, Feitosa JPA, de Paula RCM. 2005. Dynamic rheological study of Sterculia striata and karaya polysaccharides in aqueous solution. Food Hydrocolloids 19(2005):861-867.

Buck VE, Barringer SA. 2007. Factors dominating adhesion of $\mathrm{NaCl}$ onto potato chips. J Food Sci 72(8):435-441.

Butt H-J, Makowski M, Kappl M, Ptak A. 2011. On adhesion between individual particles. KONA: Powder and Particle Journal 29(2011):53-66.

Cardoso MVC, Sabadini E. 2010. The gelling of kappa-carrageenan in light and heavy water. Carbohydrate Research 345(16):2368-2373.

Castellani O, Guibert D, Al-Assaf S, Axelos M, Phillips GO, Anton M. 2010. Hydrocolloids with emulsifying capacity. Part 1 - Emulsifying properties and interfacial characteristics of conventional (Acacia senegal (L.) Wild. var. senegal) and matured (Acacia (sen) SUPER GUM) Acacia senegal. Food Hydrocolloids 24(2010):193-199.

Chandrasekaran R, Millane RP, Arnott S. 1988a. The crystal structure of gellan. Carbohydrate Research 175(1):1-15.

Chandrasekaran R, Puigjaner LC, Joyce KL, Arnott S. 1988b. Cation interactions in gellan: An x-ray study of the potassium salt. Carbohydrate Research 181(1):2340. 
Cheng Y, Brown KM, Prud'homme RK. 2002. Preparation and characterization of molecular weight fractions of guar galactomannans using acid and enzymatic hydrolysis. International Journal of Biological Macromolecules 31(1-3):29-35.

Christenson HK. 1988. Adhesion between surfaces in undersaturated vapors - a reexamination of the influence of meniscus curvature and surface forces. Journal of Colloid and Interface Science 121(1):170-178.

Churms SC, Merrifield EH, Stephen AM. 1983. Some new aspects of the molecular structure of Acacia senegal gum (gum arabic). Carbohydrate Research 123(1983):267-279.

Cleaver JAS, Tyrrell JWG. 2004. The influence of relative humidity on particle adhesion - a review of previous work and the anomalous behavior of soda-lime glass. KONA: Powder and Particle Journal 22(2004):9-22.

Connolly S, Fenyo J-C, Vandevelde M-C. 1987. Heterogeneity and homogeneity of an arabinogalactan-protein: Acacia senegal gum. Food Hydrocolloids 1(5-6):477480 .

Connolly S, Fenyo J-C, Vandevelde M-C. 1988. Effect of a proteinase on the macromolecular distribution of Acacia senegal gum. Carbohydrate Polymers 8(1988):23-32.

Cozic C, Picton L, Garda M-R, Marlhoux F, Le Cerf D. 2009. Analysis of arabic gum: Study of degradation and water desorption processes. Food Hydrocolloids 23(2009):1930-1934.

Dai L, Liu X, Liu Y, Tong Z. 2008. Concentration dependence of critical exponents for gelation in gellan gum aqueous solutions upon cooling. European Polymer Journal 44(12):4012-4019.

Dea ICM, Morris ER, Rees DA, Welsh EJ. 1977. Associations of like and unlike polysaccharides: Mechanism and specificity in galactomannans, interacting bacterial polysaccharides, and related systems. Carbohydrate Research 57(1):249272.

Dentini M, Coviello T, Burchard W, Crescenzi V. 1988. Solution properties of exocellular microbial polysaccharides. 3. Light scattering from gellan and from the exocellular polysaccharide of Rhizobium trifolii (Strain TA-1) in the ordered state. Macromolecules 21(11):3312-3320.

Desbriéres J, Hirrien M, Rinaudo M. 1998. A calorimetric study of methylcellulose gelation. Carbohydrate Polymers 37(2):145-152. 
Desbriéres J, Hirrien M, Ross-Murphy SB. 2000. Thermogelation of methylcellulose: rheological considerations. Polymer 41(7):2451-2461.

Dickinson E, Murray BS, Stainsby G, Anderson DMW. 1988. Surface activity and emulsifying behavior of some Acacia gums. Food Hydrocolloids 2(6):477-490.

Dickinson E, Elverson DJ, Murray BS. 1989. On the film-forming and emulsionstabilizing properties of gum arabic: dilution and flocculation aspects. Food Hydrocolloids 3(2):101-114.

Dopfer D, Palzer S, Heinrich S, Fries L, Antonyuk S, Haider C, Salman AD. 2012. Adhesion mechanisms between water soluble particles. Powder Technology (In Press).

Downton GE, Flores-Luna JL, King CJ. 1982. Mechanism of stickiness in hygroscopic, amorphous powders. Ind Eng Chem Fundam 21(4):447-451.

Dror Y, Cohen Y, Yerushalmi-Rozen R. 2006. Structure of gum arabic in aqueous solution. Journal of Polymer Science Part B: Polymer Physics 44(22):3265-3271.

Duvallet S, Fenyo JC, Vandevelde MC. 1989. Meaning of molecular weight measurements of gum arabic. Polymer Bulletin 21(5):517-521.

Ekström L-G, Kuivinen J. 1983. Molecular weight distribution and hydrolysis behavior of carrageenans. Carbohydrate Research 116(1):89-94.

Enggalhardjo M, Narsimhan G. 2005. Adhesion of dry seasoning particles onto tortilla chip. J Food Sci 70(3):215-222.

Fauconnier M-L, Blecker C, Groyne J, Razafindralambo H, Vanzeveren E, Marlier M, Paquot M. 2000. Characterization of two Acacia gums and their fractions using a Lagmuir film balance. Journal of Agricultural and Food Chemistry 48(7):27092712.

Fernandes PB, Goncalves MP, Doublier JL. 1991. A rheological characterization of kappa-carrageenan/galactomannan mixed gels: A comparison of locust bean gum samples. Carbohydrate Polymers 16(3):253-274.

Fincher GB, Stone BA, Clark AE. 1983. Arabinogalactan-proteins: Structure, biosynthesis, and function. Annual Review of Plant Physiology 34(1983):47-70. 
Frollini E, Reed WF, Milas M, Rinaudo M. 1995. Polyelectrolytes from polysaccharides: selective oxidation of guar gum - a revisited reaction. Carbohydrate Polymers 27(2):129-135.

Funami T, Hiroe M, Noda S, Asai I, Ikeda S, Nishinari K. 2007. Influence of molecular structure imaged with atomic force microscopy on the rheological behavior of carrageenan aqueous systems in the presence or absence of cations. Food Hydrocolloids 21(4):617-629.

Goodrum LJ, Patel A, Leykam JF, Kieliszewski MJ. 2000. Gum arabic glycoprotein contains glycomodules of both extensin and arabinogalactan-glycoproteins. Phytochemistry 54(2000):99-106.

Goycoolea FM, Morris ER, Gidley MJ. 1995. Screening for synergistic interactions in dilute polysaccharide solutions. Carbohydrate Polymers 28(4):351-358.

Gralén N, Karrholm M. 1950. The physicochemical properties of solutions of gum tragacanth. Journal of Colloid Science 5(1):21-36.

Grasdalen H, Smidsrod O. 1987. Gelation of gellan gum. Carbohydrate Polymers 7(5):371-393.

Hall LD, Yalpani M. 1980. A high-yielding, specific method for the chemical derivatization of D-galactose-containing polysaccharides: oxidation with Dgalactose oxidase, followed by reductive amination. Carbohydrate Research 81(1):C10-C12.

Halim F, Barringer SA. 2006. Electrostatic adhesion in food. J Electrostat 65(3): 168173.

Haque A, Morris ER. 1993. Thermogelation of methylcellulose. Part I: molecular structures and processes. Carbohydrate Polymers 22(3):161-173.

Harry-O'Kuru RE, Carrier CJ, Wing RE. 1999. Rheology of modified Lesquerella gum. Industrial Crops and Products 10(1999):11-20.

Hirst EL, Dunstan S. 1953. The structure of karaya gum (Cochlospermum gossypium). Journal of the Chemical Society 1953(0):2332-2337.

Hjerde T, Smidsrød O, Christensen BE. 1999. Analysis of the conformational properties of kappa- and iota-carrageenan by size-exclusion chromatography combined with low-angle laser light scattering. Biopolymers 49(1):71-80. 
Hoffman J, Svensson S. 1978. Studies of the distribution of the D-galactosyl side-chains in guaran. Carbohydrate Research 65(1):65-71.

Huang Y, Barringer SA. 2012. Adhesion of food powders with nonelectrostatic and electrostatic coating. J Food Process Eng 35(2):264-277.

Idris OHM, Williams PA, Phillips GO. 1998. Characterization of gum from Acacia senegal trees of different age and location using multidetection gel permeation chromatography. Food Hydrocolloids 12(1998):379-388.

Ikeda S, Funami T, Zhang G. 2005. Visualizing surface active hydrocolloids by atomic force microscopy. Carbohydrate Polymers 62(2005):192-196.

Jansson P-E, Lindberg B. 1983. Structural studies of gellan gum, an extracellular polysaccharide elaborated by Pseudomonas elodea. Carbohydrate Research 124(1):135-139.

Kalitnik AA, Barabanova AOB, Nagorskaya VP, Reunov AV, Glazunov VP, Solov'eva TF, Yermak IM. 2013. Low molecular weight derivatives of different carrageenan types and their antiviral activity. Journal of Applied Phycology 25(1):65-72.

Kang KA, Veeder GT, Mirrasoul PJ, Kaneko T, Cottrell IW. 1982. Agar-like polysaccharide produced by a Pseudomonas species: Production and basic properties. Applied and Environmental Microbiology 43(5):1086-1091.

Kato T, Yokoyama M, Takahashi A. 1978. Melting temperatures of thermally reversible gels IV. Methyl cellulose-water gels. Colloid and Polymer Science 256(1):15-21.

Ketkar AB, Keller DV. 1975. Adhesion of micron-sized limestone particles to a massive coal substrate. The Journal of Adhesion 7(3):235-251.

Khan T, Park JK, Kwon J-H. 2007. Functional biopolymers produced by biochemical technology considering applications in food engineering. Korean Journal of Chemical Engineering 24(5):816-826.

Kilcast D, Roberts C. 1997. Perception and measurement of stickiness in sugar-rich foods. J Texture Studies 29(1998):81-100.

Kobayashi K, Huang C-I, Lodge TP. 1999. Thermoreversible gelation of aqueous methylcellulose solutions. Macromolecules 32(21):7070-7077.

Krubal JV, Gralén N. 1948. Physicochemical properties of karaya gum and locust bean mucilage. Journal of Colloid Science. 3(1):457-471. 
Krycer I, Pope DG. 1983. An evaluation of tablet binding agents part I. Solution binders. Powder Technology 34(1):39-51.

Kuntz LA. 1994. The many benefits of salt. Food Product Design. 3(10):48-61.

Kuo M-S, Mort AJ. 1986. Identification and location of L-glycerate, an unusual acyl substituent in gellan gum. Carbohydrate Research 156(1):173-187.

Lapasin R, de Lorenzi L, Pricl S, Torriano G. 1995. Flow properties of hydroxypropyl guar gum and its long-chain hydrophobic derivatives. Carbohydrate Polymers 28(1995):195-202.

Le Cerf D, Irinei F, Muller G. 1990. Solution properties of gum exudates from Sterculia urens (karaya gum). Carbohydrate Polymers 13(1990):375-386.

Le Cerf D, Muller G. 1994. Mechanical spectroscopy of karaya gum-alginate mixed dispersions. Carbohydrate Polymers 23(4):241-246.

Lee KY, Shim J, Bae IY, Cha J, Park CS, Lee GH. 2003. Characterization of gellan/gelatin mixed solutions and gels. LWT-Food Science and Technology 36(8):795-802.

Li L, Shan H, Yue CY, Lam YC, Tam KC, Hu X. 2002. Thermally induced association and dissociation of methylcellulose in aqueous solutions. Langmuir 18(20):72917298 .

Li X, Fang Y, Al-Assaf S, Phillips GO, Nishinari K, Zhang H. 2009. Rheological study of gum arabic solutions: Interpretation based on molecular self-association. Food Hydrocolloids 23(2009):2394-2402.

Li X, Fang Y, Zhang H, Nishinari K, Al-Assaf S, Phillips GO. 2011. Rheological properties of gum arabic solution: From Newtonianism to thixotropy. Food Hydrocolloids 25(2011):293-298.

Louey MD, Mulvaney P, Stewart PJ. 2000. Characterisation of adhesional properties of lactose carriers using atomic force microscopy. J Pharmaceutical and Biomedical Analysis 25(2001):559-567.

Malvern Instruments Ltd. 2007. Mastersizer 2000 User Manual. Worcestershire, UK. Man0384 Issue 1.0. $152 \mathrm{p}$.

Mao R, Tang J, Swanson BG. 2001. Water holding capacity and microstructure of gellan gels. Carbohydrate Polymers 46(4):365-371. 
Massimilla L, Donsi G. 1976. Cohesive forces between particles of fluid-bed catalysts. Powder Technology 15(1976):253-260.

McCleary BV, Clark AH, Dea ICM, Rees DA. 1985. The fine structures of carob and guar galactomannans. Carbohydrate Research 139(1):237-260.

McFarlane JS, Tabor D. 1950. Adhesion of solids and the effect of surface films. Proceeding of the Royal Society A: Mathematical, Physical and Engineering Sciences 202(1069):224-243.

Michalski M-C, Desobry S, Hardy J. 1997. Food materials adhesion: A review. CRC Cr Rev Food Sci 37(7):591-619.

Milas M, Shi X, Rinaudo M. 1990. On the physicochemical properties of gellan gum. Biopolymers 30(3-4):451-464.

Millane RP, Chandrasekaran R, Arnott S. 1988. The molecular structure of kappacarrageenan and comparison with iota-carrageenan. Carbohydrate Research 182(1):1-17.

Mittal KL. 1977. The role of the interface in adhesion phenomena. Polymer Engineering and Science 17(7):467-473.

Mohammadifar MA, Musavi SM, Kiumarsi A, Williams PA. 2006. Solution properties of tragacanthin (water-soluble part of gum tragacanth exudate from Astragalus gossypinus). Int J Biological Macromolecules 38(2006):31-39.

Morris ER, Cutler AN, Ross-Murphy SB, Rees DA. 1981. Concentration and shear rate dependence of viscosity in random coil polysaccharide solutions. Carbohydrate Polymers 1(1):5-21.

Moritaka H, Fukuba H, Kumeno K, Nakahama N, Nishinari K. 1991. Effect of monovalent and divalent cations on the rheological properties of gellan gels. Food Hydrocolloids 4(6):495-507.

Mothé CG, Rao MA. 1999. Rheological behavior of aqueous dispersions of cashew gum and gum arabic: Effect of concentration and blending. Food Hydrocolloids 13(1999):501-506.

Murase K, Mochida T, Sagawa Y, Sugama H. 2008. Estimation on the strength of a liquid bridge adhered to three spheres. Advanced Powder Technology 19(2008):349-367. 
Nishinari K, Hofman KE, Moritaka H, Kohyama K, Nishinari N. 1997. Gel-sol transition of methylcellulose. Macromolecular Chemistry and Physics 198(4):1217-1226.

Nishinari K, Miyoshi E, Takaya T, Williams PA. 1996. Rheological and DSC studies on the interaction between gellan gum and konjac glucomannan. Carbohydrate Polymers 30(2-3):193-207.

Norton IT, Goodall DM, Morris ER, Rees DA. 1983. Role of cations in the conformation of iota and kappa carrageenan. Journal of the Chemical Society, Faraday Transactions 1: Physical Chemistry in Condensed Phases 79(10): 2475-2488.

Nussinovitch A, Hershko V. 1996. Gellan and alginate vegetable coatings. Carbohydrate Polymers 30(2):185-192.

Okamoto T, Kubota K, Kuwahara N. 1993. Light scattering study of gellan gum. Food Hydrocolloids 7(5):363-371.

O’Neil MA, Selvendran RR, Morris VJ. 1983. Structure of the acidic extracellular gelling polysaccharide produced by Pseudomonas elodea. Carbohydrate Research 124(1):123-133.

Osman ME, Menzies AR, Williams PA, Phillips GO, Baldwin TC. 1993. The molecular characterization of the polysaccharide gum from Acacia senegal. Carbohydrate Research 246(1993):303-318.

Osman ME, Menzies AR, Martin BA, Williams PA, Phillips GO, Baldwin TC. 1995. Characterization of gum arabic fractions obtained by anion-exchange chromatography. Phytochemistry 38(2):409-417.

Papadakis SE, Bahu RE. 1992. The sticky issues of drying. Drying Technology: An International Journal 10(4):817-837.

Petkowicz CLO, Reicher F, Mazeau K. 1998. Conformational analysis of galactomannans: from oligomeric segments to polymeric chains. Carbohydrate Polymers 37(1):25-39.

Picton L, Bataille I, Muller G. 2000. Analysis of a complex polysaccharide (gum arabic) by multi-angle laser light scattering coupled on-lie to size exclusion chromatography and flow field fractionation. Carbohydrate Polymers 42(2000):23-31.

Podczeck F, Newton JM, James MB. 1996. The influence of constant and changing relative humidity on the autoadhesion force between pharmaceutical powder particles. International Journal of Pharmaceuticals 145(1996):221-229. 
Podczeck F, Newton JM, James MB. 1997. Influence of relative humidity of storage air on the adhesion and autoadhesion of micronized particles to particulate and compacted powder surfaces. Journal of Colloid and Interface Science 187(1997):484-491.

Qi W, Fong C, Lamport DTA. 1991. Gum arabic glycoprotein is a twisted hairy rope. Plant Physiology 96(3):848-855.

Rafique CM, Smith F. 1950. The constitution of guar gum. Journal of the American Chemical Society 72(10):4634-4637.

Ramakrishnan S, Prud'homme RK. 2000. Effect of solvent quality and ions on the rheology and gelation of kappa-carrageenan. Journal of Rheology 44(4):885-896.

Rana V, Rai P, Tiwary AK, Singh RS, Kennedy JF, Knill CJ. 2011. Modified gums: Approaches and applications in drug delivery. Carbohydrate Polymers 83(2011):1031-1047.

Ranade MB. 1987. Adhesion and removal of fine particles on surfaces. Aerosol Science and Technology 7(2):161-176.

Randall RC, Phillips GO, Williams PA. 1988. The role of the proteinaceous component on the emulsifying properties of gum arabic. Food Hydrocolloids 2(2):131-140.

Randall RC, Phillips GO, Williams PA. 1989. Fractionation and characterization of gum from Acacia senegal. Food Hydrocolloids 3(1):65-75.

Rawle A. (Malvern Instruments Ltd.) 2008. Basic principles of particle size analysis. Worcestershire, UK: Malvern Instruments Ltd. 8 p.

Ray AK, Bird PB, Iacobucci GA, Clark BCC Jr. 1995. Functionality of gum arabic. Fractionation, characterization and evaluation of gum fractions in citrus oil emulsions and model beverages. Food Hydrocolloids 9(2):123-131.

Raymond WR, Nagel CW. 1973. Microbial degradation of gum karaya. Carbohydrate Research 30(1973):293-312.

Ren Y, Barringer SA. 2009. Adhesion of sugar and oil solutions. J Food Process Pres 33:427-435.

Richardson RK, Ross-Murphy SB. 1987. Non-linear viscoelasticity of polysaccharide solutions. 1: Guar galactomannan solutions. International Journal of Biological Macromolecules 9(5):250-256. 
Risica D, Dentini M, Crescenzi V. 2005. Guar gum methyl ethers. Part I. Synthesis and macromolecular characterization. Polymer 46(26):12247-12255.

Risica D, Barbetta A, Vischetti L, Cametti C, Dentini M. 2010. Rheological properties of guar and its methyl, hydroxypropyl and hydroxypropyl-methyl derivatives in semidilute and concentrated aqueous solutions. Polymer 51(9):1972-1982.

Robinson G, Ross-Murphy SB, Morris ER. 1982. Viscosity-molecular weight relationships, intrinsic chain flexibility, and dynamic solution properties of guar galactomannan. Carbohydrate Research 107(1):17-32.

Rochas C, Rinaudo M. 1980. Activity coefficients of counterions and conformation in kappa-carrageenan systems. Biopolymers 19(9):1675-1687.

Sanchez C, Renard D, Robert P, Schmit C, Lefebvre J. 2002. Structure and rheological properties of acacia gum dispersions. Food Hydrocolloids 16(2002):257-267.

Sanchez C, Schmitt C, Kolodziejczyk E, Lapp A, Gaillard C, Renard D. 2008. The Acacia gum arabinogalactan fraction is a thin oblate ellipsoid: A new model based on small-angle neutron scattering and ab initio calculation. Biophysical Journal 94(2):629-639.

Sarkar N. 1979. Thermal gelation properties of methyl and hydroxypropyl methylcellulose. Journal of Applied Polymer Science 24(4):1073-1087.

Sarkar N. 1995. Kinetics of thermal gelation of methylcellulose and hydroxypropylmethylcellulose in aqueous solutions. Carbohydrate Polymers 26(3):195-203.

Sarkar N, Walker LC. 1995. Hydration-dehydration properties of methylcellulose and hydroxypropylmethylcellulose. Carbohydrate Polymers 27(3):177-185.

Savage AB. Temperature-viscosity relationships for water-soluble cellulose ethers. 1957. Industrial and Engineering Chemistry 49(1):99-103.

Schubert H. 1984. Capillary forces: modeling and application in particulate technology. Powder Technology 37(1984):105-116.

Schubert H. 1987. Food particle technology. Part I: properties of particles and particulate food systems. J Food Eng 6(1987):1-32.

Shanahan MER. 1991. Adhesion and wetting: similarities and differences. Rubber World 205(1):28-36. 
Sharman WR, Richards EL, Malcolm GN. 1978. Hydrodynamic properties of aqueous solutions of galactomannans. Biopolymers 17(12):2817-2833.

Silva DA, Brito ACF, de Paula RCM, Feitosa JPA, Paula HCB. 2003. Effect of mono and divalent salts on gelation of native, $\mathrm{Na}$ and deacetylated Sterculia striata and Sterculia urens polysaccharide gels. Carbohydrate Polymers 54(2003):229-236.

Sims IM, Furneaux RH. 2003. Structure of the exudate gum from Meryta sinclairii. Carbohydrate Polymers 52(2003):423-431.

Slootmaekers D, De Jonghe C, Reynaers H, Varkevisser FA, Bloys van Treslong CJ. 1988. Static light scattering from kappa-carrageenan solutions. International Journal of Biological Macromolecules 10(3):160-168.

Slootmaekers D, van Dijk JAPP, Varkevisser FA, Bloys van Treslong CJ, Reynaers H. 1991. Molecular characterisation of kappa- and lambda-carrageenan by gel permeation chromatography, light scattering, sedimentation analysis and osmometry. Biophysical Chemistry 41(1):51-59.

Smidsrød O, Grasdalen H. 1984. Conformations of kappa-carrageenan in solution. Hydrobiologia 116-117(1):178-186.

Soltani M, Ahmadi G. 1994. On particle adhesion and removal mechanisms in turbulent flows. J Adhes Sci Technol 8(7):763-85.

Suderman DR, Cunningham FE. 1981. Effect of freezing broiler drumsticks on breading adhesion. J Food Sci 46(6):1953, 1955.

Sumonsiri N, Barringer SA. 2011. Effect of sodium chloride and food target properties on nonelectrostatic and electrostatic coating. J Electrostat 69(2011):578-586.

Takahashi R, Tokunou H, Kubota K, Ogawa E, Oida T, Kawase T, Nishinari K. 2004. Solution properties of gellan gum: Change in chain stiffness between single- and double-stranded chains. Biomacromolecules 5(2):516-523.

Takenaka N, Ogata K, Yabe T, Yamauchi R, Kato K. 2006. Effect of oil and sugar contents on the surface of dehulled-roasted sesame seeds on adhesion between the seeds. J Food Sci 71(6):303-307.

Tanaka F. 1996. Phase formation of associating polymers: gelation, phase separation and microphase formation. Advances in Colloid and Interface Science 63(1996):2340. 
Tanaka F, Ishida M. 1995. Thermoreversible gelation of hydrated polymers. Journal of the Chemical Society, Faraday Transactions 91(16):2663-2670.

Tardos G, Gupta R. 1996. Forces generated in solidifying liquid bridges between two small particles. Powder Technology 87(1996):175-180.

Tischer CA, Iacomini M, Gorin PAJ. 2002. Structure of the arabinogalactan from gum tragacanth (Astragalus gummifer). Carbohydrate Research 337(2002):1647-1655.

Verbeken D, Dierckx S, Dewettinck K. 2003. Exudate gums: occurrence, production, and applications. Appl Microbiol Biotechnol 63(2003):10-21.

Viebke C, Piculell L, Nilsson S. 1994. On the mechanism of gelation of helix-forming biopolymers. Macromolecules 27(15):4160-4166.

Viebke C, Borgström J, Piculell L. 1995. Characterization of kappa- and iota-carrageenan coils and helices by MALLS/GPC. Carbohydrate Polymers 27(2):145-154.

Viebke C, Williams PA. 2000. Determination of molecular mass distribution of kappacarrageenan and xanthan using asymmetrical flow field-flow fractionation. Food Hydrocolloids 14(3):265-270.

Vinod VTP, Sashidhar RB, Sarma VUM, Satyanarayana Raju S. 2010. Comparative amino acid and fatty acid compositions of edible gums kondagogu (Cochlospermum gossypium) and karaya (Sterculia urens). Food Chemistry 123(2010):57-62.

Williams PA, Phillips GO, Stephen AM. 1990. Spectroscopic and molecular comparisons of three fractions from Acacia senegal gum. Food Hydrocolloids 4(4):305-311.

Yáñez-Ferández J, Ramos-Ramírez EG, Salazar-Montoya JA. 2008. Rheological characterization of dispersions and emulsions in the preparation of microcapsules obtained by interfacial polymerization containing Lactobacillus sp. European Food Research and Technology 226(5):957-966.

Yokoyama A, Srinivasan KR, Fogler HS. 1988. Stabilization mechanism of colloidal suspensions by gum tragacanth: the influence of $\mathrm{pH}$ on stability. Journal of Colloid and Interface Science 126(1):141-149.

Yuguchi Y, Thuy TTT, Urakawa H, Kajiwara K. 2002. Structural characteristics of carrageenan gels: temperature and concentration dependence. Food Hydrocolloids 16(6):515-522. 


\section{Appendix A: Particle Size of Powders}

Table 1 Particle Size of Powders

\begin{tabular}{|l|r|}
\hline \multicolumn{1}{|c|}{ Powder } & $\mathrm{D}[\mathbf{4 ,}$ 3] $(\boldsymbol{\mu \mathrm { m } )}$ \\
\hline Coarse Salt & 483.68 \\
\hline Special Flake Salt & 430.75 \\
\hline Flake Salt & 393.77 \\
\hline Fine Flake Salt & 253.66 \\
\hline Fine Salt & 57.60 \\
\hline Cocoa Powder & 136.55 \\
\hline Cheese A & 91.52 \\
\hline Cheese B & 119.11 \\
\hline BBQ & 289.57 \\
\hline Sour Cream \& Onion & 161.40 \\
\hline Ranch & 185.44 \\
\hline
\end{tabular}




\section{Appendix B: Solution Concentration}

Table 2 Solution Concentrations Capable of being Sprayed

\begin{tabular}{|r|c|c|c|c|c|c|c|}
\hline $\begin{array}{c}\text { Spray } \\
\text { Concentration }\end{array}$ & Arabic & Karaya & Gellan & K-Carrageenan & MC (41 kDa) & Tragacanth & Guar \\
\hline $20.000 \%$ & $\mathbf{X}$ & & & & & & \\
\hline $10.000 \%$ & $\mathbf{X}$ & & & & & & \\
\hline $5.000 \%$ & $\mathbf{X}$ & & & & & & \\
\hline $2.500 \%$ & $\mathbf{X}$ & $\mathbf{X}$ & & & & & \\
\hline $1.000 \%$ & $\mathbf{X}$ & $\mathbf{X}$ & $\mathbf{X}$ & $\mathbf{X}$ & $\mathbf{X}$ & & \\
\hline $0.500 \%$ & $\mathbf{X}$ & $\mathbf{X}$ & $\mathbf{X}$ & $\mathbf{X}$ & $\mathbf{X}$ & $\mathbf{X}$ & $\mathbf{X}$ \\
\hline $0.250 \%$ & $\mathbf{X}$ & $\mathbf{X}$ & $\mathbf{X}$ & $\mathbf{X}$ & $\mathbf{X}$ & $\mathbf{X}$ & \\
\hline $0.125 \%$ & & $\mathbf{X}$ & & & $\mathbf{X}$ & $\mathbf{X}$ & $\mathbf{X}$ \\
\hline $0.063 \%$ & & & & & & & $\mathbf{X}$ \\
\hline $0.031 \%$ & & & & & & & $\mathbf{X}$ \\
\hline $0.016 \%$ & & & & & & & \\
\hline
\end{tabular}




\section{Appendix C: Powder Hydrophobicity}

Table 3 Partition of Powder Components into Aqueous and Cyclohexane or Hexane Phases for Determination of Powder Hydrophobicity

\begin{tabular}{|l|c|c|c|c|c|c|}
\hline & $\mathrm{NaCl}$ & Cheese & Barbecue & Ranch & $\begin{array}{c}\text { Sour Cream \& } \\
\text { Onion }\end{array}$ & Cocoa \\
\hline Cyclohexane & - & $25 \%$ & $43 \%$ & $48 \%$ & $49 \%$ & - \\
\hline Water & - & $75 \%$ & $57 \%$ & $52 \%$ & $51 \%$ & - \\
\hline & & & & & & \\
\hline Hexane & $0 \%$ & $2 \%$ & $2 \%$ & $6 \%$ & $36 \%$ & $98 \%$ \\
\hline Water & $100 \%$ & $98 \%$ & $98 \%$ & $94 \%$ & $64 \%$ & $2 \%$ \\
\hline & & & & & & \\
\hline Hexane & $0 \%$ & $2 \%$ & $10 \%$ & $31 \%$ & $11 \%$ & $98 \%$ \\
\hline Interface & - & $55 \%$ & $28 \%$ & $38 \%$ & $40 \%$ & - \\
\hline Water & $100 \%$ & $43 \%$ & $62 \%$ & $31 \%$ & $49 \%$ & $2 \%$ \\
\hline
\end{tabular}

